\title{
High Spatio-Temporal Resolution Mapping of Soil Moisture by Integrating Wireless Sensor Network Observations and MODIS Apparent Thermal Inertia in the Babao River Basin, China
}

\author{
Jian Kang ${ }^{1}$, Rui Jin ${ }^{1,2,}$, Xin $\mathrm{Li}^{1,2}$, Chunfeng Ma ${ }^{1}$, Jun Qin ${ }^{3}$ and Yang Zhang ${ }^{1}$ \\ 1 Heihe Remote Sensing Experimental Research Station, Key Laboratory of Remote Sensing of Gansu Province, Northwest Institute of \\ Eco-Environment and Resources, Chinese Academy of Sciences, Lanzhou 730000, China; kangjian@1zb.ac.cn; jinrui@1zb.ac.cn; \\ lixin@1zb.ac.cn; machf@1zb.ac.cn; zhangyang@1zb.ac.cn \\ 2 CAS Center for Excellence in Tibetan Plateau Earth Sciences, Chinese Academy of Sciences, Beijing 100101, China; \\ 3 Laboratory of Tibetan Environment Changes and Land Surface Processes, Institute of Tibetan Plateau Research, Chinese Academy of \\ Sciences, P.O. Box 2871, Beijing 100101, China; shuairenqin@itpcas.ac.cn \\ * Correspondence: E-Mail: jinrui @1zb.ac.cn; Tel.: +86-931-4967965; Fax: +86-931-8279161
}

Abstract: Soil moisture distributions with high spatio-temporal resolution are scarce but beneficial for understanding eco-hydrological processes and closing the water cycle at the basin scale. Sensor networks are innovative in their ability to capture the spatio-temporal heterogeneity and dynamics of soil moisture; however, they cannot be used to directly derive spatially continuous soil moisture distributions. A Bayesian-based upscaling algorithm that utilizes MODIS-derived apparent thermal inertia is used to map daily soil moisture spatial patterns with a resolution of $1 \mathrm{~km}$ in the Babao River Basin, China. The 2-4 cm soil moisture observations from seven automatic meteorological stations located in different elevation zones from $3000 \mathrm{~m}$ to $3500 \mathrm{~m}$ are employed to validate the mapping algorithm. The correlation coefficient and unbiased root-mean-square error (RMSE) averaged 0.880 and $0.031 \mathrm{~cm} 3 / \mathrm{cm} 3$, respectively, which indicate satisfactory estimation accuracy. The $1 \mathrm{~km}$ resolution soil moisture products are re-sampled to a resolution of $25 \mathrm{~km}$ and then compared to the level 3 Soil Moisture and Ocean Salinity Mission (SMOS) soil moisture product. The results show that both products exhibit strong temporal consistency; however, due to complex topography, the SMOS soil 
moisture is generally lower than that of the upscaling results. Semivariograms and an empirical orthogonal function (EOF) analysis are used to analyze the space-time heterogeneities of soil moisture at the $1 \mathrm{~km}$ scale. In the summer, rainfall results in soil moisture with low spatial variability and a complex spatial structure. After the rainy season, the spatial heterogeneity of soil moisture is affected by other factors, such as soil texture, evapotranspiration and topography. From the perspective of temporal variation, the upscaled soil moisture shows a well-defined seasonal cycle, which represents the effects of decreased rainfall from August to October. Because more rain falls in the summer due to the mountain microclimate, the oscillation in soil moisture is more pronounced over twenty percent of the area compared to that in other regions. Based on a validation analysis of the mapping results, the upscaling method is proven feasible, and the upscaled soil moisture can be used to analyze eco-hydrological processes and validate remote sensing products.

Keywords: Empirical Orthogonal Function; Heterogeneity; High resolution; Soil Moisture; Spatio-temporal mapping; Upscaling

\section{Introduction}

The high spatio-temporal resolution of soil moisture distributions plays an important role in ecological and hydrological processes at the basin scale. From the perspective of ecology, soil moisture is related to plant growth (Rodriguez-Iturbe, Porporato, Laio, \& Ridolfi, 2001) and influences the structure, function and diversity of vegetation, especially in arid and semiarid regions (Rodríguez-Iturbe \& Porporato, 2004). From a hydrologic perspective, soil moisture controls the rainfall-runoff response, particularly when the soil is already saturated (Dunne, Moore, \& Taylor, 1975). Eco-hydrological processes cannot be studied without models. The lack of soil moisture data 
with high spatio-temporal resolutions is one of the largest sources of uncertainty in such models. Therefore, at the basin scale, high spatio-temporal resolution soil moisture products can be used to understand eco-hydrological processes, calibrate parameters in hydrological models, and improve the prediction ability of hydrological data assimilation systems.

There are two primary ways to periodically obtain spatio-temporal maps of soil moisture. First, because of its cost-effective nature and large-scale observation capability, remote sensing has been widely applied to retrieve soil moisture at global and regional scales, particularly using microwave remote sensing, such as brightness temperatures obtained from the Soil Moisture and Ocean Salinity Mission (SMOS), Soil Moisture Active Passive Mission (SMAP), Advanced Microwave Scanning Radiometer (AMSR-E) and Conical Scanning Microwave Imager/Sounder (CMIS) and backscattering derived from the Advanced Scatterometer (ASCAT) (Reichle, Koster, Dong, \& Berg, 2004; Wagner et al., 2003). However, the soil moisture remote sensing products currently available and operable have resolutions of $25-40 \mathrm{~km}$, which cannot meet the requirements of water cycle research and water resource management at the basin scale. Although SAR systems (ERS-1/2, Radarsat-1, ENVISAT ASAR and JERS-1) have resolutions ranging from a few meters to the sub-meter level, the influences of surface roughness and vegetation cover limit SAR retrieval, and the repeat cycle of SAR is generally irregular and longer than 15 days. In addition to remote sensing technology, meteorological analysis systems are used to output reanalysis data sets, such as NCEP/NCAR (Kalnay et al., 1996), ECMWF (Uppala et al., 2005) and JRA-25 (Onogi et al., 2007), which provide global soil moisture products at the highest resolution, i.e., $0.25^{\circ}$. In addition, global land data assimilation (GLDAS) can generate real-time soil moisture data with $0.25^{\circ}$ and $1^{\circ}$ resolutions from 1979 to present (Rui \& Beaudoing, 2011). These simulated or assimilated soil moisture products are highly dependent on 
atmospheric forcing. However, observations of key forcing parameters, such as air temperature, precipitation, wind speed and humidity, are sparse. Therefore, it is difficult to accurately simulate soil moisture dynamics at the basin scale.

Thus, the aforementioned methods may not be optimal for providing the spatio-temporal characteristics of soil moisture at the basin scale. The distributed wireless sensor network (WSN), which is a revolutionary technique in Earth system science, has been applied to capture the spatio-temporal variability of soil moisture in several research projects, such as the Critical Zone Observatories (Anderson, Bales, \& Duffy, 2008), the Terrestrial Environmental Observatories (Zacharias et al., 2011) and the Heihe Watershed Allied Telemetry Experimental Research (HiWATER) studies (Jin et al., 2014; Kang et al., 2014; Li et al., 2013).

To meet the requirements of hydrological modeling and remote sensing applications, an upscaling method is necessary to convert multi-point WSN soil moisture observations to a grid format covering an entire basin. The commonly used algorithms include inverse distance weighting (IDW), linear regression and Kriging to upscale the soil moisture based on multi-point observations (Yao et al., 2013). Hengl (2007) proposed principles for determining a suitable method depending on the auxiliary data and spatial autocorrelation of a variable. The spatial autocorrelation represents the characteristics of soil moisture, which has been proven in previous studies (Bárdossy \& Lehmann, 1998; Kumar et al., 2016). When there are no auxiliary data, Kriging is better than IDW for mapping soil moisture. If the corresponding auxiliary data related to soil moisture are available, Kriging with a linear regression model (RK) is optimal compared to linear regression alone (Kang, Jin, \& Li, 2015). However, RK is unable to handle the nonlinear relationship between soil moisture and the auxiliary data. Gao et al. (2014) employed Bayesian maximum entropy (BME) to obtain high estimation accuracy when solving 
nonlinear expressions related to soil moisture. All the above methods require numerous observation sites to capture the spatial characteristics of soil moisture, and determining the spatial autocorrelation is challenging using only a few observation sites. However, in a basin with complex topography, the WSN distribution would appear sparse, regardless of its spatial coverage and density. Therefore, it is infeasible to map soil moisture based on the above methods in a mountainous area with drastic terrain relief.

In this study, we analyze the spatio-temporal distribution and dynamic characteristics of soil moisture at the basin scale, especially under complex topography conditions, and attempt to derive high spatio-temporal resolution maps of soil moisture by integrating WSN multi-point observations and auxiliary remote sensing information. A Bayesian-based upscaling algorithm and MODIS-derived apparent thermal inertia are used to estimate daily soil moisture at a resolution of $1 \mathrm{~km}$. The estimation accuracy is evaluated based on automatic meteorological stations (AMSs) and the SMOS soil moisture product. Finally, the mapping results are analyzed to understand the spatio-temporal characteristics of soil moisture.

\section{Study Area and Data}

\subsection{Study Area}

The Babao River Basin is the main area of hydrological research in the cold region of the Heihe Watershed Allied Telemetry Experimental Research (HiWATER) project (Li et al., 2013), which is the eastern branch of the upper reach of the Heihe River Basin (HRB). Mountain runoff is the main water resource that is allocated between water consumption for agricultural production in the middle reach of 
the HRB and the water requirements of the ecological environment in the downstream region of the HRB.

The Babao River Basin has an area of $2,495 \mathrm{~km}^{2}$ and is located in the upper reach of the Heihe River Basin, northwestern China (Figure 1). The elevation ranges from 2,640 $\mathrm{m}$ to 5,000 $\mathrm{m}$, and the average elevation is $3,604 \mathrm{~m}$. The annual mean air temperature is approximately $0.7^{\circ} \mathrm{C}$, which indicates that a freezing and thawing cycle exists in the study area. The frozen soil in the study region primarily represents seasonal frozen soil, and the lower elevation boundary of permafrost ranges from 3,650 m to $3,700 \mathrm{~m}$. The rainy season spans from May to September in the Babao River Basin, and most rainfall events occur in summer (from June to August). The annual rainfall is approximately $400 \mathrm{~mm}$, and it gradually decreases from southeast to northwest. Additionally, rainfall increases with elevation to $3,650 \mathrm{~m}$, above which it decreases. In the rainy season, rainfall influenced by the mountain microclimate frequently occurs in the afternoon, leading to a heterogeneous distribution of rainfall. Rainfall results in rapid changes in soil moisture in the Babao River Basin, and the spatial patterns of soil moisture are also affected by topography. Generally, soil moisture associated with shady slopes is higher than that associated with sunny slopes. The land cover exhibits vertically zonal characteristics. There is low vegetation coverage in the cold desert zone at elevations exceeding 3,800 m; alpine meadows appear in the elevation range from 2,600 $\mathrm{m}$ to $3,800 \mathrm{~m}$; and there is a small amount of forest (picea crassifolia) near 3,100 m. There are several soil types, such as loam, sandy loam, loamy sand, etc., and the surface soil consists primarily of sand (65\% 85\%) and silt (13\% 30\%). Along the northern and southern slopes, the soil layer has a depth of approximately $40 \mathrm{~cm}$, and there are large amounts of gravel at depths exceeding $40 \mathrm{~cm}$. In the valley region, the soil layer depth is $70-80 \mathrm{~cm}$, beyond which gravel appears. 


\subsection{Data}

The Ecological and Hydrological Wireless Sensor Network (EHWSN) was established in July 2013 in the Babao River Basin (Figure 1) (Ge et al., 2015; Jin et al., 2014). It includes 40 nodes that measure soil moisture and soil temperature at depths of 4, 10 and $20 \mathrm{~cm}$ at 5-minute intervals. The EHWSN nodes are installed at an average distance of ten kilometers and at an average altitude of 3581 $\mathrm{m}$. Based on the integrity of the data, 32 nodes are selected to upscale soil moisture. Due to the strong heterogeneity of soil moisture, auxiliary data related to soil moisture must be introduced. MODIS 8-day surface reflectance (SR, MOD09A1) and daily land surface temperature (LST, MOD11A1) data are employed to derive the Apparent Thermal Inertia (ATI) as auxiliary data. Due the different spatial resolution between SR $(500 \mathrm{~m})$ and LST $(1 \mathrm{~km})$, each $2 \times 2$ group of cells in the SR product is averaged to produce $1 \mathrm{~km}$ cell values from left to right and top to bottom. Then, ATI data are combined with the EHWSN observations to upscale soil moisture to a resolution of $1 \mathrm{~km}$. Because snow cover results in ATI values that do not truly reflect the spatial pattern of soil moisture, the period from August 2013 to October 2013 is selected due to the lack of snow.

The $4 \mathrm{~cm}$ soil moisture observations from the A'rou superstation and six automatic meteorological stations (AMSs) (10.3972/hiwater.182.2014.db, 10.3972/hiwater.181.2014, 10.3972/hiwater.180.2014, 10.3972/hiwater.179.2014.db, 10.3972/hiwater.177.2014.db, and 10.3972/hiwater.176.2014.db) are used to validate the upscaling results. The $25 \mathrm{~km}$ soil moisture product from SMOS is compared to the upscaling results to analyze the consistency of the data sets. The $25 \mathrm{~km}$ Level 3 SMOS soil moisture data are produced by the Barcelona Expert Centre (BEC, http://cp34-bec.cmima.csic.es/). Level 3 soil moisture products are computed by plotting the Level 2 Soil Moisture User Data Product (UDP) onto a 
spatially averaged regular latitude-longitude grid with a resolution of $25 \mathrm{~km}$. The detailed relevant information and station locations are shown in Table 1 and Table 2, respectively.

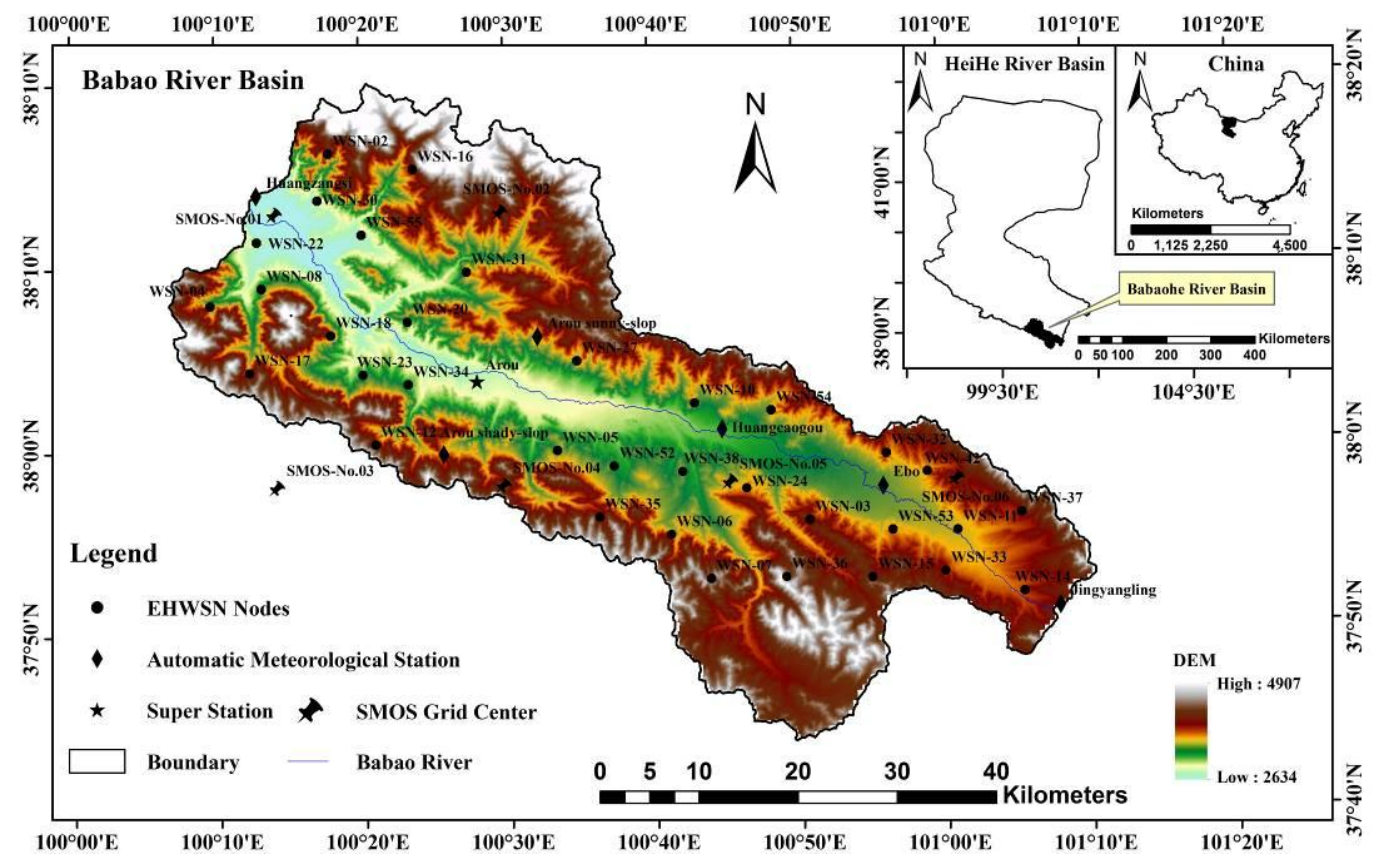

Figure 1. Map of the Babao River Basin and the distribution of the EHWSN nodes

Table 1. Relevant information

\begin{tabular}{|c|c|c|c|c|c|c|}
\hline Data Type & Data Source & $\begin{array}{c}\text { Coordinate } \\
\text { System }\end{array}$ & Date & $\begin{array}{l}\text { Temporal } \\
\text { resolution }\end{array}$ & $\begin{array}{c}\text { Spatial } \\
\text { resolution }\end{array}$ & $\begin{array}{c}\text { Observation } \\
\text { depth }\end{array}$ \\
\hline \multirow{3}{*}{$\begin{array}{l}\text { In-situ soil } \\
\text { moisture } \\
\text { measurements }\end{array}$} & EHWSN $^{*}$ & WGS84 & & 5 minutes & & \multirow{3}{*}{$4 \mathrm{~cm}$} \\
\hline & AMS & longitude/ & & 10 minutes & & \\
\hline & $\begin{array}{c}\text { A'rou } \\
\text { superstation }\end{array}$ & $\begin{array}{c}\text { latitude } \\
\text { coordinate }\end{array}$ & & 10 minutes & & \\
\hline \multirow{3}{*}{$\begin{array}{c}\text { Remote } \\
\text { sensing } \\
\text { information }\end{array}$} & $\begin{array}{l}\text { MODIS SR } \\
(\text { MOD09A1) }\end{array}$ & sinusoidal & $\begin{array}{l}\text { August } \\
2013 \text { to }\end{array}$ & 8 days & $500 \mathrm{~m}$ & \multirow{3}{*}{$\begin{array}{l}\text { surface } \\
\text { layer }\end{array}$} \\
\hline & $\begin{array}{c}\text { MODIS LST } \\
(\text { MOD11A1) }\end{array}$ & project & $\begin{array}{c}\text { October } \\
2013\end{array}$ & Daily & $1 \mathrm{~km}$ & \\
\hline & $\begin{array}{l}\text { SMOS soil } \\
\text { moisture }\end{array}$ & $\begin{array}{c}\text { cylindrical } \\
\text { equal-area } \\
\text { project }\end{array}$ & & 3 days & $25 \mathrm{~km}$ & \\
\hline
\end{tabular}

The projection coordinates of the remote sensing data have been transformed to longitude/latitude coordinates to match the coordinates of the in-situ data. All asterisk-marked data are used in the soil moisture upscaling, and the unmarked data are used to validate the upscaling results. 
Table 2. Spatial locations of the A'rou superstation, AMSs and EHWSN nodes

\begin{tabular}{|c|c|c|c|c|}
\hline Station & Type & $\begin{array}{l}\text { Longitude } \\
\quad\left({ }^{\circ}\right) \\
\end{array}$ & $\begin{array}{c}\text { Latitude } \\
\left({ }^{\circ}\right)\end{array}$ & $\begin{array}{c}\text { Elevation } \\
(\mathrm{m})\end{array}$ \\
\hline A'rou & Superstation & 100.464 & 38.047 & 3033 \\
\hline E'bo & AMS & 100.915 & 37.949 & 3294 \\
\hline Huangcaogou & AMS & 100.731 & 38.003 & 3137 \\
\hline Huangzangsi & AMS & 100.192 & 38.225 & 2612 \\
\hline Jingyangling & AMS & 101.116 & 37.838 & 3750 \\
\hline $\begin{array}{l}\text { A'rou sunny } \\
\text { slope }\end{array}$ & AMS & 100.520 & 38.090 & 3529 \\
\hline $\begin{array}{l}\text { A'rou shady } \\
\text { slope }\end{array}$ & AMS & 100.411 & 37.984 & 3536 \\
\hline WSN-01 & EHWSN & 100.228 & 38.068 & 3538 \\
\hline WSN-02 & EHWSN & 100.282 & 38.258 & 3818 \\
\hline WSN-03 & EHWSN & 100.830 & 37.920 & 3829 \\
\hline WSN-05 & EHWSN & 100.541 & 37.986 & 3356 \\
\hline WSN-06 & EHWSN & 100.671 & 37.908 & 3635 \\
\hline WSN-07 & EHWSN & 100.716 & 37.868 & 4204 \\
\hline WSN-08 & EHWSN & 100.203 & 38.136 & 3348 \\
\hline WSN-10 & EHWSN & 100.700 & 38.027 & 3478 \\
\hline WSN-11 & EHWSN & 101.000 & 37.908 & 3449 \\
\hline WSN-12 & EHWSN & 100.333 & 37.994 & 3813 \\
\hline WSN-14 & EHWSN & 101.075 & 37.852 & 3611 \\
\hline WSN-15 & EHWSN & 100.901 & 37.867 & 3843 \\
\hline WSN-16 & EHWSN & 100.379 & 38.243 & 3766 \\
\hline WSN-17 & EHWSN & 100.189 & 38.060 & 3671 \\
\hline WSN-18 & EHWSN & 100.282 & 38.093 & 3792 \\
\hline WSN-20 & EHWSN & 100.371 & 38.105 & 3242 \\
\hline WSN-23 & EHWSN & 100.319 & 38.057 & 3270 \\
\hline WSN-24 & EHWSN & 100.758 & 37.949 & 3513 \\
\hline WSN-27 & EHWSN & 100.565 & 38.067 & 3414 \\
\hline WSN-30 & EHWSN & 100.269 & 38.216 & 3091 \\
\hline WSN-31 & EHWSN & 100.440 & 38.149 & 3462 \\
\hline WSN-32 & EHWSN & 100.919 & 37.979 & 3580 \\
\hline WSN-33 & EHWSN & 100.985 & 37.871 & 3661 \\
\hline WSN-34 & EHWSN & 100.371 & 38.048 & 3239 \\
\hline WSN-35 & EHWSN & 100.589 & 37.925 & 3767 \\
\hline WSN-36 & EHWSN & 100.802 & 37.868 & 4182 \\
\hline WSN-37 & EHWSN & 101.074 & 37.923 & 3744 \\
\hline WSN-38 & EHWSN & 100.685 & 37.965 & 3413 \\
\hline
\end{tabular}




\begin{tabular}{lllll} 
WSN-52 & EHWSN & 100.606 & 37.971 & 3335 \\
WSN-53 & EHWSN & 100.925 & 37.909 & 3526 \\
WSN-54 & EHWSN & 100.788 & 38.020 & 3484 \\
WSN-55 & EHWSN & 100.319 & 38.184 & 3045 \\
\hline
\end{tabular}

\section{Methodology}

\subsection{Upscaling Method}

Spatial interpolation methods are generally used to upscale target variables, and the interpolation accuracy depends primarily on the number of samples and the sample distribution. Because of the strong heterogeneity of soil moisture, few spatially distributed observation stations are generally available, especially in mountainous areas with complex terrain. Therefore, due to the sparsity of the EHWSN, with an average of approximately ten kilometers between nodes, spatial interpolation methods are not applicable. In fact, EHWSN measurements can roughly capture the temporal pattern of soil moisture in each upscaled pixel, although the oscillation magnitude and the range of upscaled soil moisture are lost and must be controlled by introducing additional information.

In the Babao River Basin, ATI provides additional information and can be used to describe the spatial distribution of soil moisture (Ma, Wang, Han, \& Li, 2013). ATI can be computed using the MODIS albedo and LST products as follows (Peters, De Baets, De Clercq, Ducheyne, \& Verhoest, 2011; Veroustraete et al., 2012; Verstraeten, Veroustraete, van der Sande, Grootaers, \& Feyen, 2006):

$$
\tau^{a t i}=A \frac{1-\omega}{\Delta T}
$$

where $A$ is the solar correction factor. $\omega$ represents the surface albedo and is calculated using the MODIS SR product based on the conversion formula developed by Liang (2001). $\Delta T$ denotes the 
maximum daily amplitude of land surface temperature and can be directly derived from the MODIS LST product during the day (10:30 am) and night (22:30 pm).

ATI time series information can be used to capture the temporal changes in upscaled soil moisture and can aid in establishing a relationship between EHWSN measurements and upscaled soil moisture (Qin et al., 2013). Assuming that the transformation function between the EHWSN measurements and the upscaled grids is linear, the upscaled soil moisture $\theta_{t}^{\text {upscaling }}$ in a grid from time $t_{1}$ to $t_{M}$ can be represented as follows:

$$
\theta_{t}^{u p s c a l i n g}=\mathbf{D}_{t}^{E H W S N_{-} o b s} \beta,
$$

where $\theta_{t}^{\text {upscaling }}$ indicates a column vector $\left[\theta_{t_{1}}^{\text {upscaling }}, \theta_{t_{2}}^{\text {upscaling }}, \theta_{t_{3}}^{\text {upscaling }} \cdots, \theta_{t_{M}}^{\text {upscaling }}\right]^{T} . \beta$ is the vector of combination coefficients $\left[\beta_{0}, \beta_{1}, \beta_{3}, \cdots, \beta_{N}\right]^{T} . \beta_{0}$ represents a constant term, and $\beta_{N}$ is the weighted coefficient of the Nth EHWSN observation node. $\mathbf{D}_{t}^{E H W S N_{-} o b s}$ is the observation matrix $[M, N+1]:$

$$
\left[\begin{array}{ccccc}
1 & \theta_{t_{1}, 1}^{E H W S N_{-} o b s} & \theta_{t_{1}, 2}^{E H W S N_{-} o b s} & \cdots & \theta_{t_{1}, N}^{E H W N_{-} o b s} \\
1 & \theta_{t_{2}, 1}^{E H W S N_{-} o b s} & \theta_{t_{2}, 2}^{E H W S N_{\_} o b s} & \cdots & \theta_{t_{2}, N}^{E H W N_{-} o b s} \\
\vdots & \vdots & \vdots & \ddots & \vdots \\
1 & \theta_{t_{M}, 1}^{E H W S N_{-} o b s} & \theta_{t_{M}, 2}^{E H W S N_{-} o b s} & \cdots & \theta_{t_{M}, N}^{E H W S N_{-} o b s}
\end{array}\right],
$$

where $\theta_{t_{M}, N}^{E H W S N_{-} o b s}$ represents the EHWSN observation of the $N$ th node at time $t_{M}$ and $M$ is the number of time series observations.

To determine the combination coefficients $\beta, \theta_{t}^{\text {upscaling }}$ samples are required to capture the temporal variability of soil moisture in the upscaled grid during the period from $t_{1}$ to $t_{M}$. In practice, it is difficult to obtain samples of soil moisture at the grid scale using current observation techniques. However, the samples can be replaced by a representative soil moisture $\theta_{t}^{\text {rep }}$ with random noise, which can be derived based on the relationship between ATI estimated by remote sensing and soil 
moisture. An empirical relationship between surface soil moisture observed by the EHWSN and ATI can be formulated to obtain representative soil moisture information. The regression relationship is as follows:

$$
\theta^{E H W S N_{-} o b s}=f\left(\tau^{a t i}\right)+\varepsilon
$$

where $\theta^{\text {EHWSN_obs }}$ represents the EHWSN observations, $\tau^{\text {ati }}$ represents the ATI at grid points corresponding to the in-situ measurements and $\varepsilon$ represents random error. $f(\cdot)$ represents the relationship function. It is difficult to construct a daily relationship model because the absence of ATI caused by clouds results in few available pairs in the ATI and EHWSN observations. A reasonable regression model requires at least 50 samples; hence, all matched pairs in the time series are used to estimate $f(\cdot)$ in this study.

ATI can be transformed into representative soil moisture $\theta_{t}^{\text {rep }}$ using Equation (4). Then, Equation (2) can be rewritten as follows:

$$
\theta_{t}^{r e p}=\mathbf{D}_{t^{\prime}}^{E H W N_{-} o b s} \beta+\mathbf{E},
$$

where the number of elements in $\theta_{t}^{\text {rep }}$ can be less than or equal to $M . \mathbf{D}_{t^{\prime}}^{\text {EHWSN_obs }}$ is extracted from $\mathbf{D}_{t}^{E H W S N_{-} o b s}$ according to the observation time of $\theta_{t}^{\text {rep }} . \mathbf{E}$ is an error term and satisfies the $N(0, C)$ assumption.

Generally, an ordinary least squares (OLS) analysis is performed to determine $\beta$ by minimizing $J$ :

$$
J=\left(\mathbf{D}_{t^{\prime}}^{\text {EHWS } \_o b s} \beta-\theta_{t}^{\text {rep }}\right)^{\mathrm{T}}\left(\mathbf{D}_{t^{\prime}}^{\text {EHWSN_obs }} \beta-\theta_{t}^{\text {rep }}\right) .
$$


However, it is not sufficient to simply minimize errors because overfitting can occur if a statistical model describes the error instead of the true relationship. The overfitting effect may generate a model with poor predictive performance. To prevent this situation, a regularization term is combined with Equation (6):

$$
J=\left(\mathbf{D}_{t^{\prime}}^{E H W S N_{-} o b s} \beta-\theta_{t}^{\text {rep }}\right)^{\mathrm{T}} \mathbf{C}^{-1}\left(\mathbf{D}_{t^{\prime}}^{E H W N_{\_} o b s} \beta-\theta_{t}^{\text {rep }}\right)+\alpha \beta^{\mathrm{T}} \beta,
$$

where $\mathbf{C}=\sigma^{2} \mathbf{I}$ and $\sigma$ denotes the standard deviation of $\theta_{t}^{\text {rep }} . \alpha$ is the regularization parameter.

To calculate the optimal parameter $\beta$, we take the derivative of $J$ and set the derivative equal to zero:

$$
\frac{\partial J}{\partial \beta}=2\left(\mathbf{D}_{t^{\prime}}^{E H S N_{-} o b s}\right)^{-1} \mathbf{C}^{-1}\left[\mathbf{D}_{t^{\prime}}^{E H W S N_{-} o b s} \beta-\theta_{t}^{r e p}\right]+2 \alpha \beta=0
$$

thus,

$$
\hat{\beta}=\left[\left(\mathbf{D}_{t^{\prime}}^{E H W S N_{-} o b s}\right)^{\mathrm{T}} \mathbf{C}^{-1} \mathbf{D}_{t^{\prime}}^{E H W S N_{-} o b s}+\alpha \mathbf{I}\right]^{-1}\left(\mathbf{D}_{t^{\prime}}^{E H W S N_{-} o b s}\right)^{\mathrm{T}} \mathbf{C}^{-1} \theta_{t}^{r e p},
$$

where $\alpha$ is unknown and can be estimated using several methods, such as the discrepancy principle (Hansen, 1998), generalized cross-validation (Golub, Heath, \& Wahba, 1979), the quasi-optimality criterion (Bakushinskii, 1984), and the L-curve criterion (Hansen, Nagy, \& Leary, 2007). In this paper, a Bayesian method is used to determine $\alpha$ (Qin et al., 2013). The estimator of the upscaled soil moisture $\theta_{t}^{\text {upscaling }}$ in Equation (2) at a grid point during the period from $t_{1}$ to $t_{M}$ is as follows:

$$
\hat{\theta}_{t}^{\text {upscaling }}=\mathbf{D}_{t}^{E H W S N_{-} o b s} \hat{\beta},
$$

where $\mathbf{D}_{t}^{\text {EHWSN_obs }}$ is the same as that in Equation (2). The estimated $\hat{\theta}_{t}^{\text {upscaling }}$ values fill the spatio-temporal gaps in the representative soil moisture data set based on the temporal continuity in the EHWSN observations. 


\subsection{Mapping Procedure}

All upscaled grids are consistent with the $1 \mathrm{~km}$ ATI scale and are composed of 144 rows and 84 columns, which covers the Babao River Basin. The schematic diagram shows the mapping procedure (Figure 2) as follows:

(1) Calculate the ATI using the MODIS SR and LST products for each grid from August 2013 to October 2013 according to Equation (1). Due to clouds, the ATI may be temporally discontinuous.

(2) Construct a logarithmic relationship between the ATI and soil moisture observed by the EHWSN according to Equation (4)

(3) Transform the ATI into representative soil moisture to capture the variability in the upscaled soil moisture for a grid. The temporal continuity of the representative soil moisture is the same as the ATI.

(4) Formulate a linear equation (Equation 5) between $\theta_{t}^{\text {rep }}$ and $\mathbf{D}_{t^{\prime}}^{\text {EHWSN_obs }}$ for a grid.

(5) Estimate the weight coefficient vector $\beta$ according to Equation (9) for the selected gird in step (4).

(6) Obtain the time series of upscaled soil moisture from August 2013 to October 2013 using Equation (10).

(7) Repeat step (4) to step (6) to upscale soil moisture in other grids one at a time. Finally, the continuous spatio-temporal soil moisture map is generated. 


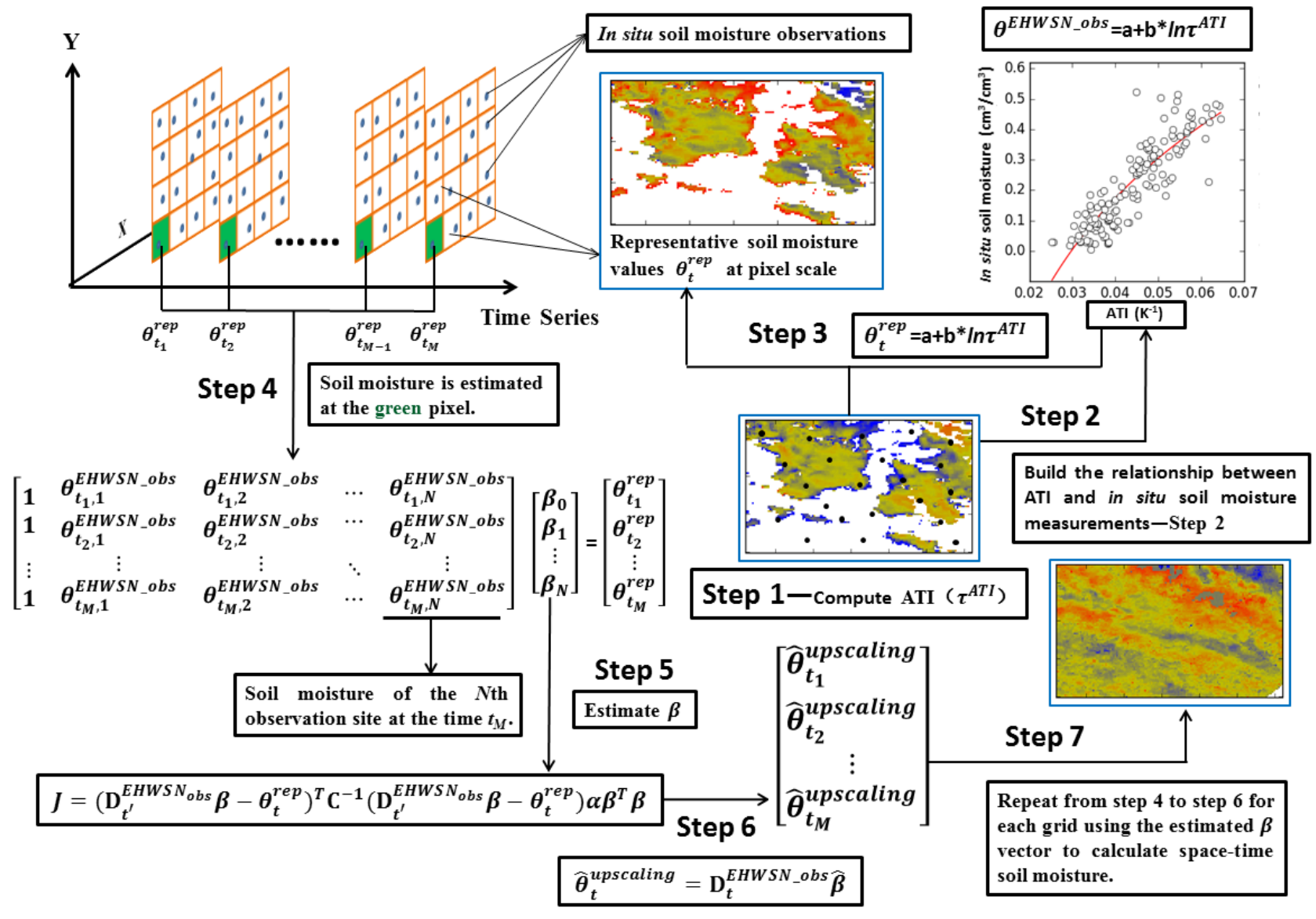

Figure 2. Mapping procedure of spatio-temporal soil moisture in the Babao River Basin

\subsection{Validation of the Upscaling Method}


A statistical index, the root-mean-square error (RMSE), is widely used to directly quantify the errors of upscaled products of soil moisture using in-situ measurements. Because of the different spatial representativeness, an overall bias may occur between site observations and upscaled soil moisture data in the time series. The RMSE is sensitive to the bias and cannot provide an exact accuracy estimation. However, the range of error with time around the mean can be used to assess the accuracy by removing the bias. A more reliable evaluation approach called the unbiased RMSE (ubRMSE) (Pratola, Barrett, Gruber, Kiely, \& Dwyer, 2014) is used to compare the upscaled soil moisture pixels with AMS observations. The $u b \mathrm{RMSE}$ is defined as follows:

$$
u b \mathrm{RMSE}=\sqrt{\frac{1}{N} \sum_{n=1}^{N}\left(\left(\theta_{\text {Upscaling }}-\bar{\theta}_{\text {Upscaling }}\right)-\left(\theta_{I n-\text { situ }}-\bar{\theta}_{I n-\text { situ }}\right)\right)^{2}},
$$

where $N$ is the number of AMS observations in the time series and $\theta_{U p s c a l i n g}$ and $\theta_{I n-s i t u}$ are the upscaled soil moisture and AMS measurements, respectively. $\bar{\theta}_{U p s c a l i n g}$ and $\bar{\theta}_{I n-s i t u}$ are the mean values of the time series.

In addition to the error evaluation, it is necessary to assess the consistency between data sets, and the following correlation coefficient is adopted:

$$
r=\frac{\sum_{i=1}^{N}\left[\theta_{\text {Upscaling }}-\bar{\theta}_{\text {Upscaling }}\right]\left[\theta_{I n-\text { situ }}-\bar{\theta}_{I n-\text { situ }}\right]}{\sqrt{\sum_{i=1}^{N}\left[\theta_{\text {Upscaling }}-\bar{\theta}_{U p s c a l i n g}\right]^{2} \cdot \sum_{i=1}^{N}\left[\theta_{I n-s i t u}-\bar{\theta}_{I n-s i t u}\right]^{2}}} .
$$

\subsection{Spatial and Temporal Analysis Methods of the Upscaled Soil Moisture Products}


First, the spatial heterogeneity (including structure and variability) and time variability of the upscaled $1 \mathrm{~km}$ soil moisture product are analyzed based on the EHWSN observations and MODIS-derived ATI.

A semivariogram based on geostatistical techniques is adopted to analyze the spatial heterogeneity of soil moisture (Journel \& Huijbregts, 1978). The classical estimator of a semivariogram, called semivariance, is defined as follows:

$$
\hat{\gamma}(h)=\frac{1}{2 N(h)} \sum_{i=1}^{N(h)}[\mathrm{Z}(x+h)-\mathrm{Z}(x)]^{2},
$$

where $N(h)$ is the number of experimental pairs $[\mathrm{Z}(x), \mathrm{Z}(x+h)]$ with distance $h$ and $Z(x)$ is the value at location $x$, which corresponds to the soil moisture content in this study. The spatial heterogeneity of soil moisture can be described by Gaussian, spherical and exponential semivariogram models, as shown in many previous studies (Kang et al., 2014; Kumar, Arora, \& Hariprasad, 2016; Western, Blöschl, \& Grayson, 1998; Western et al., 2004). The semivariogram of soil moisture is obtained by fitting the semivariance $\hat{\gamma}(h)$ using these three models, which are expressed by three key parameters: major range $(a)$, nugget $\left(C_{0}\right)$ and partial sill $\left(C_{1}\right)$.

$$
\left\{\begin{array}{l}
\text { Spherical }: C_{0}+C_{1}\left[\frac{3 h}{2 a}-\frac{1}{2}\left(\frac{h}{a}\right)^{3}\right] \\
\text { Gaussian: } C_{0}+C_{1}\left[1-\exp \left(-\left(\sqrt{3} \frac{h}{a}\right)^{2}\right)\right] \\
\text { Exponential }: C_{0}+C_{1}\left[1-\exp \left(-3 \frac{h}{a}\right)\right]
\end{array}\right.
$$

In Equation (14), the three model functions represent the variability at the spatial scale $h$. The parameter $a$ denotes the spatial correlation distance, which is a measurement of the spatial continuity of a variable. The parameter $a$ is used to interpret the spatial structure of a variable. The sill (the sum of 
$C_{0}$ and $C_{1}$ ) is close to the spatial variance of a variable and is an indicator of the spatial variability. A non-zero $C_{0}$ can be a result of random measurement error and fine-scale variance.

The strong surface heterogeneity leads to differences in temporal changes in a land surface variable at different locations. To explain the temporal variations, an empirical orthogonal function (EOF) analysis is used to reduce the dimensionality of the spatio-temporal fields and identify the most important patterns (Hannachi, 2004). The spatio-temporal fields at locations $s_{1}, s_{2}, \cdots s_{p}$ and times $t_{1}, t_{2}, \cdots t_{n}$ can be described by a matrix:

$$
\mathbf{F}=\left[\begin{array}{cccc}
x_{t_{1} s_{1}} & x_{t_{1} s_{2}} & \cdots & x_{t_{1} s_{p}} \\
x_{t_{2} s_{1}} & \ddots & \cdots & \vdots \\
\vdots & \cdots & \ddots & \vdots \\
x_{t_{n} s_{1}} & x_{t_{n} s_{2}} & \cdots & x_{t_{n} s_{p}}
\end{array}\right]
$$

where the column vector $\left[\begin{array}{llll}x_{t_{1} s_{p}} & x_{t_{2} s_{p}} \ldots, x_{t_{n} s_{p}}\end{array}\right]^{\mathrm{T}}$ denotes a soil moisture time series at location $s_{p}$. The row vector $\left[x_{t_{n} s_{1}}, x_{t_{n} s_{2}} \ldots, x_{t_{n} s_{p}}\right]$ represents a map or field at time $t_{n}$. The EOF is performed using $\mathbf{F}$ as the data matrix, whose covariance matrix $\mathbf{R}$ is constructed and diagonalized to solve for the eigenvalues and corresponding eigenvectors as follows:

$$
\mathbf{R}=\mathbf{U} \mathbf{\Lambda} \mathbf{V},
$$

where $\mathbf{R}=\frac{1}{n-1} \mathbf{F}^{\mathrm{T}} \mathbf{F}$ and $\mathbf{U}=\mathbf{V}^{\mathrm{T}} . \mathbf{\Lambda}$ is a diagonal matrix containing the eigenvalues $\lambda_{i}$ of $\mathbf{R}$. The column vectors of $\mathbf{U}$ are eigenvectors of $\mathbf{R}$ corresponding to the eigenvalues $\lambda_{i}$. The eigenvector related to the largest eigenvalue is called EOF1, and the eigenvector related to the second largest eigenvalue is EOF2, etc. The eigenvalue $\lambda_{i}$ corresponding to the $i$ th EOF gives a measure of the variance explained by EOF $i$, which is written as a percentage: $\frac{100 \lambda_{i}}{\operatorname{tr}(\boldsymbol{\Lambda})} \%$. To observe how EOFs evolve over time, the spatio-temporal fields are projected onto the EOFs: 


$$
\mathbf{P}=\mathbf{F U}
$$

where the $i$ th column vector of $\mathbf{P}$ represents the time series of EOF $i$, which is called the $i$ th principal component $(\mathrm{PC} i)$.

Because of the insignificant noise in the orthogonal decomposition of $\mathbf{R}$, a significance test with a 95\% confidence interval is used to determine the error range of the eigenvalues $\lambda_{i}$ (North, Bell, Cahalan, \& Moeng, 1982):

$$
e_{i}=\lambda_{i}\left(\frac{2}{n}\right)^{\frac{1}{2}}
$$

where $n$ is the number of time series. If two adjacent eigenvalues $\left[\lambda_{i}, \lambda_{i+1}\right]$ meet $\lambda_{i}-\lambda_{i+1} \geq e_{i}$, the EOF $i$ corresponding to $\lambda_{i}$ is effective.

\section{Results}

\subsection{Upscaled $1 \mathrm{~km}$ Soil Moisture}

Alpine meadow is the primary land cover type in the Babao River Basin. Although the estimation accuracy of ATI is affected by vegetation, a monotonically increasing natural logarithm function was fitted with a goodness of fit value of 0.651 , as shown in Figure 3, which indicates the high correlation between the ATI and EHWSN soil moisture observations. Thus, the ATI can be used to represent the spatial distribution of soil moisture in the Babao River Basin. 


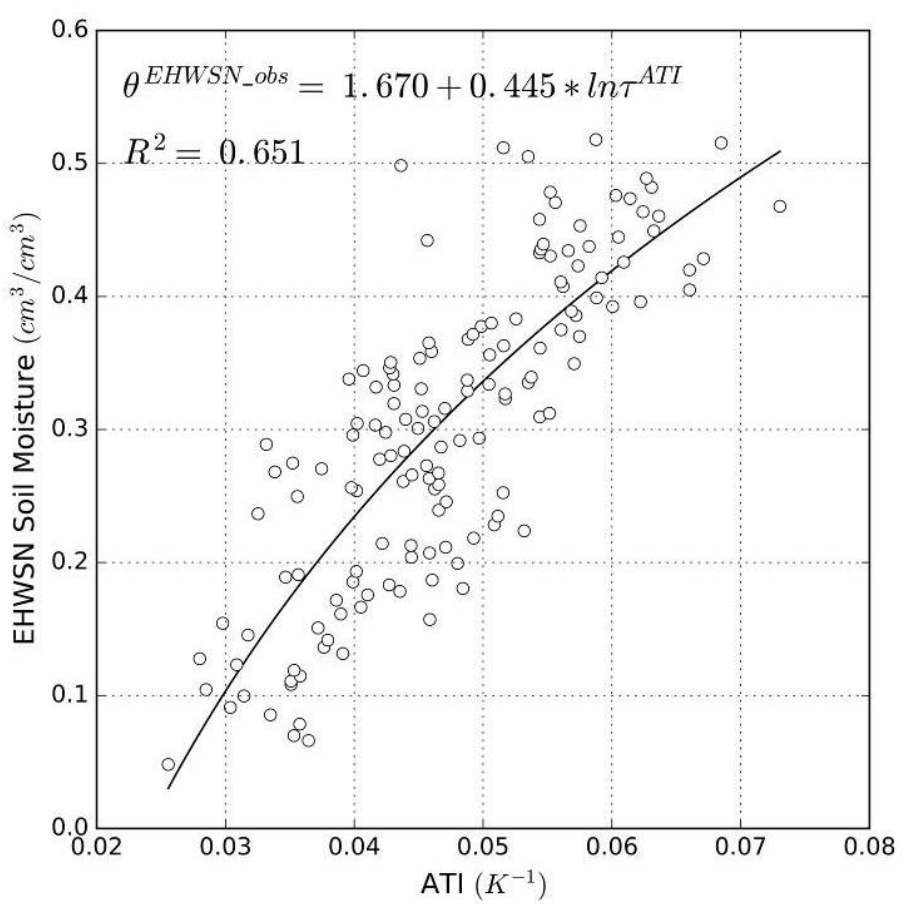

Figure 3. Relationship between the MODIS-derived ATI and EHWSN soil moisture observations

According to Equation (1), the MODIS 8-day surface reflectance products were used to derive albedo, which was combined with MODIS daily LST products to calculate the daily ATI from August 1, 2013, to October 22, 2013. The ATI values over 6 days are shown in Figure 4a. Due to cloud cover, the LST was often missing. Moreover, the availability of ATI depends on the data quality of LST. The ATI data were not available in approximately $40 \%$ of the study area from August 2013 to October 2013; however, the data can capture changes in soil moisture. The ATI values in the valley were much lower than those in the mountains, and the ATI values on the south slope of the Babao River Basin were higher than those on the north slope due to higher albedo and lower maximum daily amplitude of LST on the south slope according to Equation (1).

According to Equation (5), representative soil moisture information is required to estimate the weight coefficients of each EHWSN node. The relationship function in Figure 3 was used to transform 
the ATI into representative soil moisture (Figure 4b). Although the ATI can also be used to directly estimate soil moisture, it is difficult to determine the continuous spatio-temporal variability in soil moisture due to space-time discontinuity associated with ATI, which is affected by clouds.

In this study, representative soil moisture is used to describe the temporal variability in soil moisture at a particular grid point. The variability can be expressed as a linear combination of EHWSN nodes. The spatial gaps due to discontinuous ATI data were filled using temporally continuous EHWSN observations (Equation 10). The daily soil moisture data with a resolution of $1 \mathrm{~km}$ are shown in Figure 5, which shows not only the spatial characteristics of the representative soil moisture data but also the detailed spatio-temporal distribution of soil moisture relative to the representative soil moisture. The spatial changes in soil moisture are primarily determined by rainfall in August. The south slope of the Babao River Basin endures frequent rainfall in summer due to the windward slope location and low evaporation, which results in higher soil moisture than that in the wide valley and north slope regions. After the rainy season, the average soil moisture in the Babao River Basin decreased, with a more rapid decrease in the wide valley and on the north slope. 

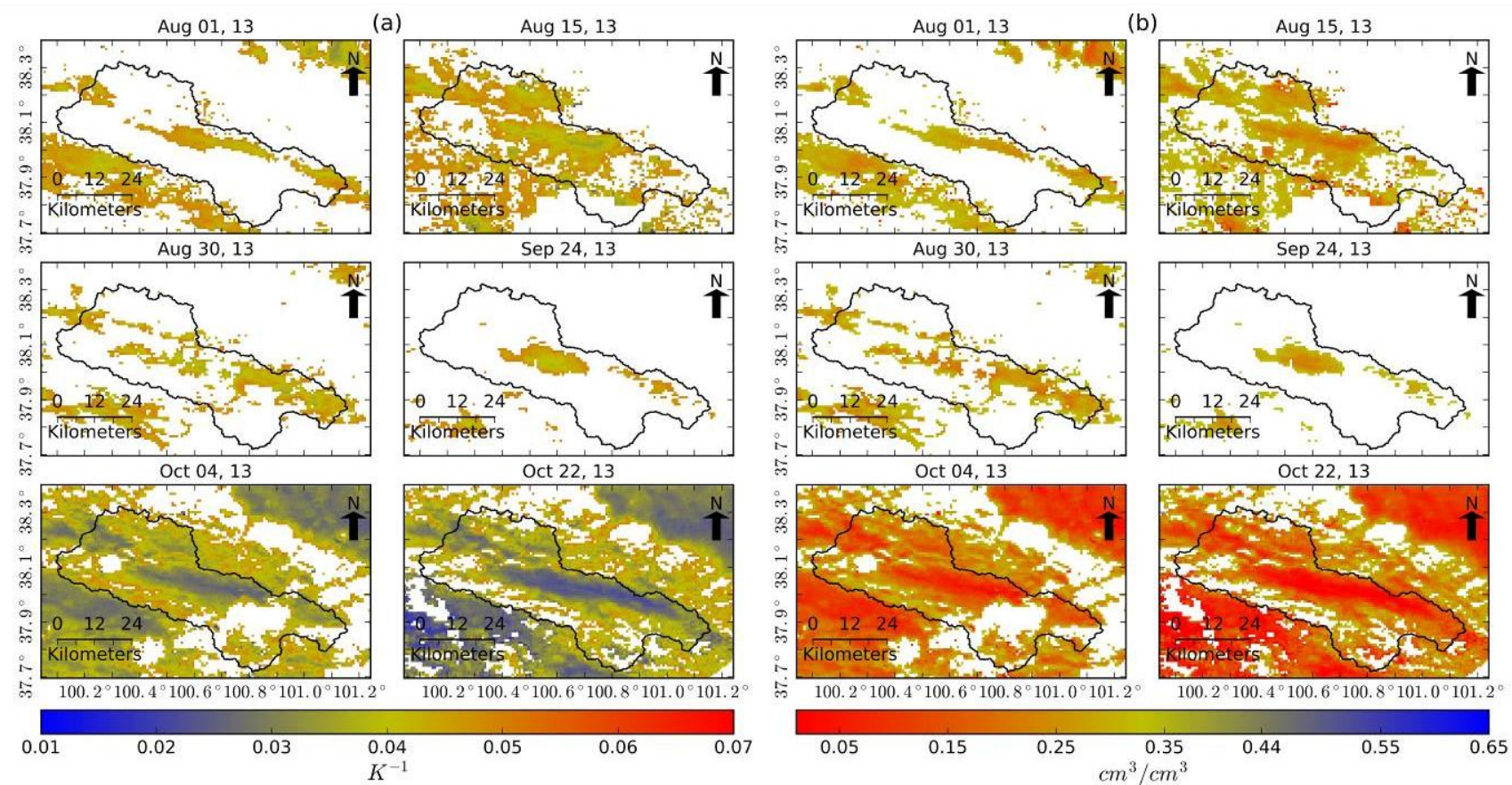

Figure 4. ATI (a) and representative soil moisture (b) in the Babao River Basin

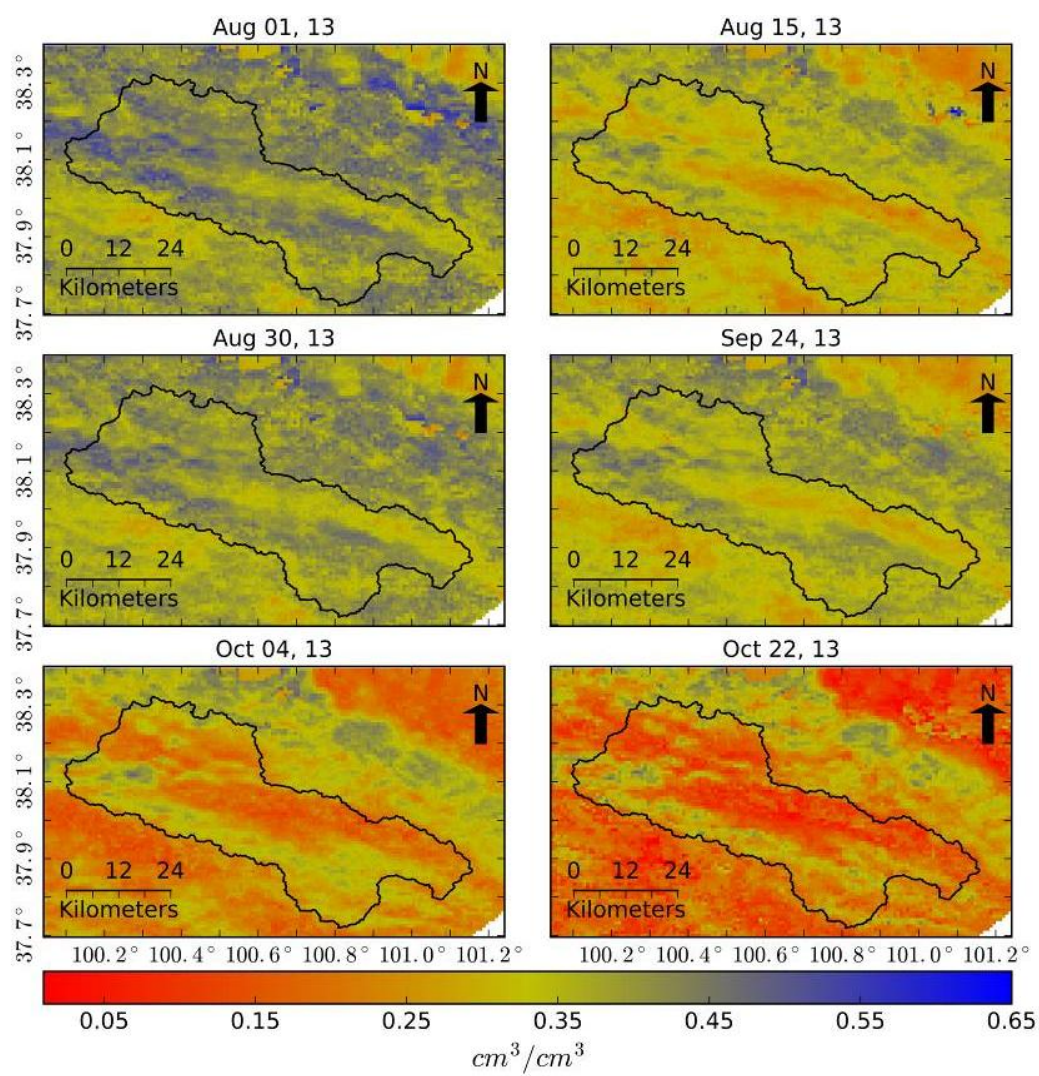

Figure 5. Spatio-temporal mapping results of $1 \mathrm{~km}$ soil moisture in the Babao River Basin 


\subsection{Validations}

4.2.1. Point-scale validation based on surface soil moisture observations at the AMSs

Because of the scale mismatch between the station observations and remote sensing pixels, a direct validation of the upscaled $1 \mathrm{~km}$ soil moisture data set using the point-scale AMSs measurements was not possible. Both data sets had a mean bias of $0.088 \mathrm{~cm}^{3} / \mathrm{cm}^{3}$ and a maximum bias of approximately $0.179 \mathrm{~cm}^{3} / \mathrm{cm}^{3}$, and the bias was obtained by calculating the absolute difference between the temporal means of in-situ and upscaled soil moisture; thus, the ubRMSE index was used to evaluate the upscaled soil moisture. During the period from August 2013 to October 2013, the ranges of soil moisture error associated with the upscaling results and AMS observations were calculated by removing the mean values of the time series (Figure 6).

Table 3 illustrates satisfactory estimation accuracy, with mean $u b$ RMSE and $r$ values of 0.031 $\mathrm{cm}^{3} / \mathrm{cm}^{3}$ and 0.892 , respectively. The evaluation accuracy of the upscaled soil moisture at Huangzangsi station was lowest, with an $u b$ RMSE of $0.046 \mathrm{~cm}^{3} / \mathrm{cm}^{3}$ and $r$ of 0.721 . The upscaled soil moisture validated using the Huangzangsi station observations includes information from several land cover types, such as cropland, buildings, roads, grassland, etc. The strong surface heterogeneity increased the range of error in soil moisture and decreased the consistency in the time series between the Huangzangsi station observations and the upscaled soil moisture. The next lowest evaluation accuracy associated with upscaled soil moisture was at the A'rou superstation, with an $u b$ RMSE of $0.035 \mathrm{~cm}^{3} / \mathrm{cm}^{3}$ and $\mathrm{r}$ of 0.868 . The upscaled soil moisture evaluated at the A'rou superstation for the same land cover type (grassland) as the other six AMSs except Huangzangsi station did not exhibit 
high accuracy. A rat infestation led to the destruction of soil and vegetation, which enhanced the surface heterogeneity.

The soil moisture showed drastic fluctuations due to frequent rainfall events. The dynamic changes in soil moisture became stable after September 20. The differences in the statistical characteristics before and after September 20 were well defined, with average ubRMSEs of 0.025 and 0.020 , respectively, and average $r$ values of 0.748 and 0.903 , respectively. The rainfall events introduced uncertainty in the mapping process and resulted in mapping errors. 

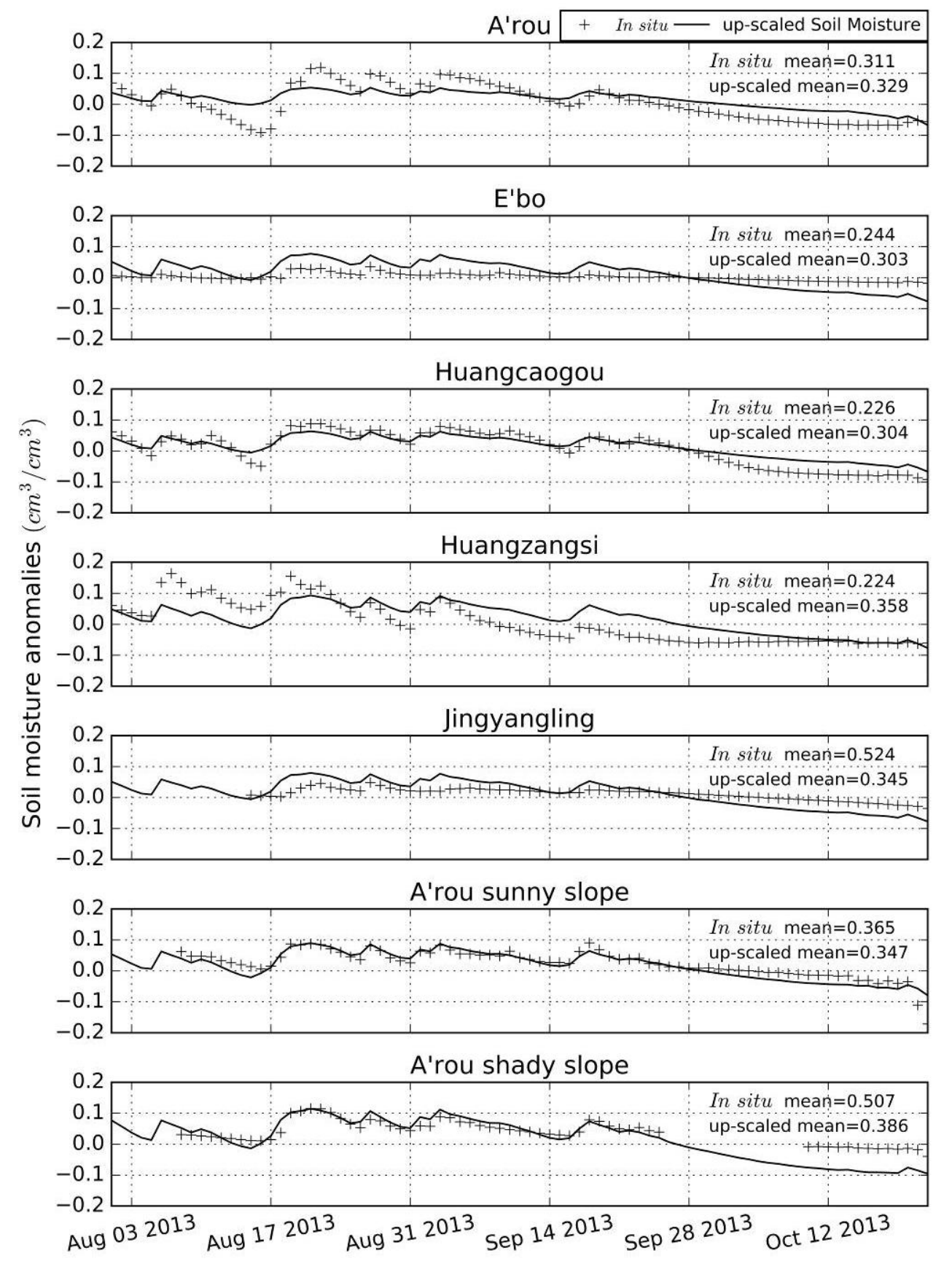

Figure 6. Temporal evolution of the fluctuations in upscaled soil moisture and AWS observations

Table 3. Correlation coefficient and $u b$ RMSE between the upscaled soil moisture and AMS observations

\begin{tabular}{ccc}
\hline Station & $r$ & $u b$ RMSE \\
\hline A'rou & 0.868 & 0.035 \\
E'bo & 0.903 & 0.031 \\
Huangcaogou & 0.974 & 0.023
\end{tabular}




\begin{tabular}{ccc} 
Huangzangsi & 0.721 & 0.046 \\
Jingyangling & 0.933 & 0.029 \\
A'rou sunny slope & 0.909 & 0.019 \\
A'rou shady slope & 0.936 & 0.033 \\
\hline
\end{tabular}

4.2.2. Comparison of the spatial pattern of upscaled soil moisture to SMOS products

Comparisons between different remote sensing products of soil moisture are effective for evaluating accuracy. However, there is no $1 \mathrm{~km}$ remote sensing product of soil moisture that can be compared to the upscaled soil moisture data set. Currently, the resolution of soil moisture remote sensing products is confined to $25-40 \mathrm{~km}$. To indirectly evaluate the upscaled soil moisture, the upscaled soil moisture was re-sampled at the same spatial scale as the $25 \mathrm{~km}$ L-band SMOS product by averaging all upscaled $1 \mathrm{~km}$ pixels in SMOS grids. The SMOS product was influenced less by vegetation relative to the other products, and the six SMOS soil moisture grids cover the Babao River Basin.

As shown in Figure 7, most of the points were below the 1:1 lines, indicating that the SMOS soil moisture product in the Babao River Basin was largely underestimated relative to the re-sampled soil moisture at a spatial scale of $25 \mathrm{~km}$. The RMSEs between both data sets were large, as shown in Table 4, averaging $0.120 \mathrm{~cm}^{3} / \mathrm{cm}^{3}$. The retrieval accuracy of the passive microwave soil moisture data was found to be sensitive to topography through a change in emissivity with viewing angle and a change in vegetation path length. Previous studies have used the slope to reduce retrieval errors (Sandells, Davenport, \& Gurney, 2008). The RMSEs were consistent with the complex topography represented by the slope indexes, especially for the mean slope in the SMOS pixels, suggesting that the underestimated SMOS soil moisture values increased with increasing topographical complexity in the Babao River Basin. 
The high consistency illustrated by the fitted lines in Figure 7 between the SMOS product and the re-sampled $25 \mathrm{~km}$ soil moisture was proven by $\mathrm{F}$ test, which showed highly significant relativities at the $p<0.01$ level. The correlation coefficients $r$ in Table 4 were also used to evaluate the consistency in the time series. The average $r$ was 0.719 , indicating a substantial correlation.
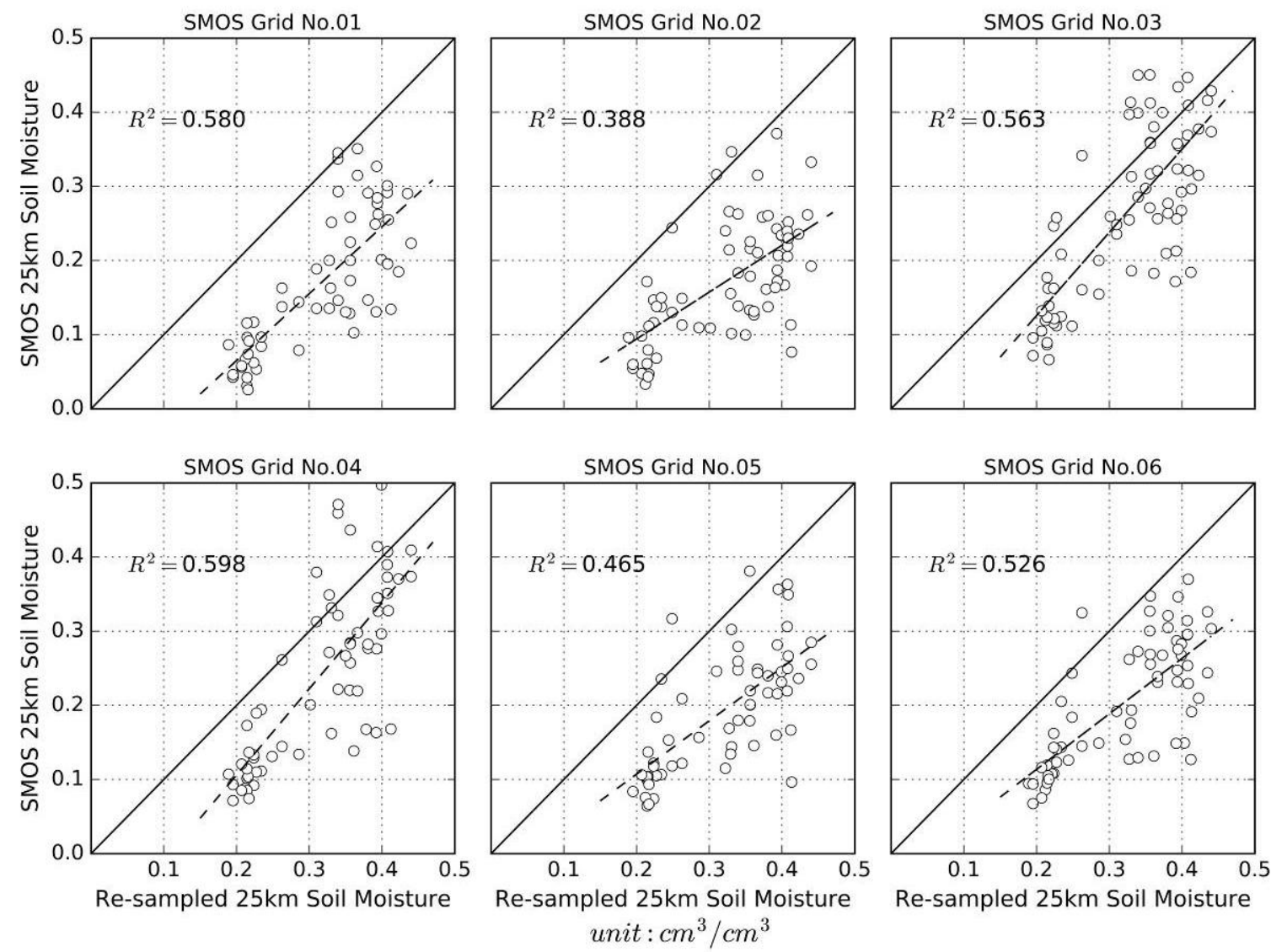

Figure 7. Scatterplots of re-sampled soil moisture at a resolution of $25 \mathrm{~km}$ and soil moisture from the SMOS product from August 2013 to October 2013

Table 4. Correlation coefficients, RMSEs and linear equations between the SMOS product (Y) and upscaling results at a resolution of $25 \mathrm{~km}(\mathrm{X})$

\begin{tabular}{ccccccc}
\hline Grid & Mean of & Standard Deviation & & RMSE & Linear equation & $\begin{array}{c}p \text { value } \\
\text { Number }\end{array}$ \\
\hline
\end{tabular}




\begin{tabular}{lcccccc}
\hline Grid No. 01 & 10.612 & 5.779 & 0.762 & 0.147 & Y=0.902*X-0.115 & $2.519 \times 10^{-12}$ \\
Grid No. 02 & 11.017 & 5.422 & 0.623 & 0.152 & Y=0.632*X-0.032 & $1.375 \times 10^{-8}$ \\
Grid No. 03 & 4.209 & 4.836 & 0.75 & 0.083 & Y=1.122*X-0.099 & $3.398 \times 10^{-14}$ \\
Grid No. 04 & 6.659 & 4.574 & 0.774 & 0.092 & Y=1.164*X-0.127 & $6.741 \times 10^{-14}$ \\
Grid No. 05 & 7.380 & 4.781 & 0.682 & 0.129 & Y=0.720*X-0.037 & $1.425 \times 10^{-9}$ \\
Grid No. 06 & 7.151 & 4.841 & 0.725 & 0.119 & Y=0.748*X-0.036 & $8.433 \times 10^{-12}$ \\
\hline
\end{tabular}

\subsection{Spatial and Temporal Analysis of Upscaled Soil Moisture}

\subsubsection{Semivariogram Analysis}

The spatial autocorrelation of soil moisture expressed by semivariograms has been discussed in previous studies. Spatial autocorrelation in the upscaled soil moisture suggests that the upscaling results are reasonable. The spatial autocorrelation of upscaled soil moisture can be determined based on the agreement between the theoretical semivariogram model and the semivariance of upscaled soil moisture. The three universal semivariogram models in Equation (14) were compared, and the optimal theoretical model with the smallest residual sum of squares relative to the semivariance was selected. Figure 8 illustrates excellent matches between semivariograms and semivariance values, and these matches suggest that high spatial autocorrelation exists. Moran's I index was introduced to quantify the global spatial autocorrelation. The closer the value of Moran's I is to 1, the stronger the spatial autocorrelation. In the upscaling time windows, the average Moran's I was 0.826, and the maximum and minimum Moran's I were 0.900 and 0.725 , respectively. The high Moran's I indicated that the spatial heterogeneity of the upscaled soil moisture could be analyzed using semivariograms. 

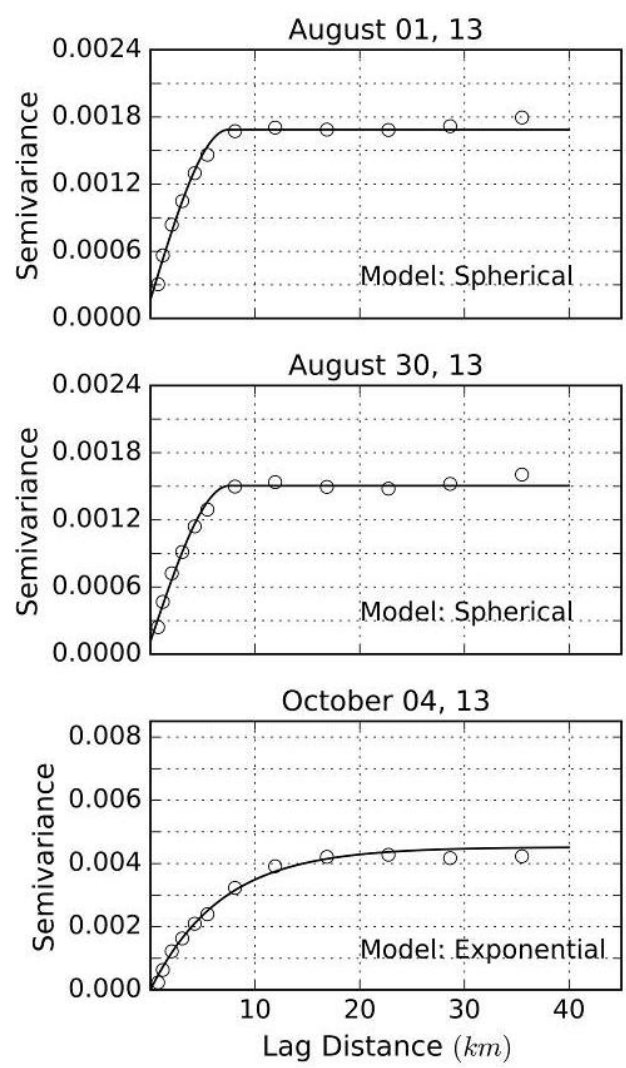

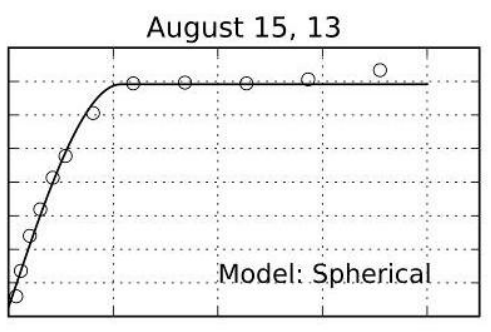

September 24,13

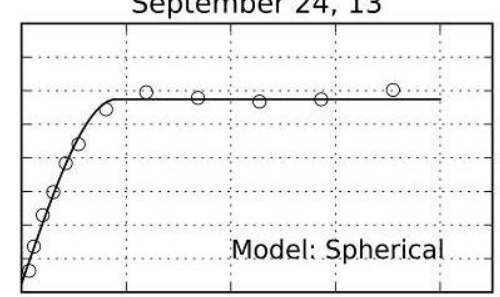

October 22,13

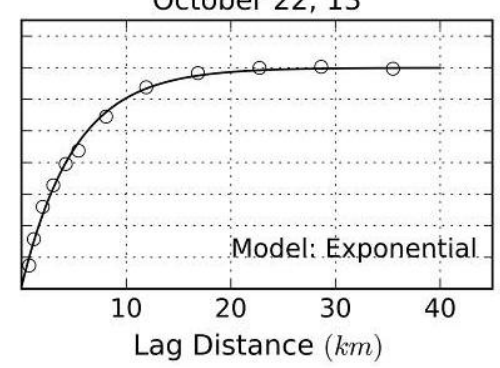

Figure 8. Examples of the theoretical (line) and experimental (marker) semivariograms of upscaled soil moisture at a resolution of $1 \mathrm{~km}$

A global heterogeneity analysis of upscaled soil moisture is displayed in Figure 9. As shown in Figures 9a and 9b, during the period from August to October, the average soil moisture in the mapping area exhibited a downward trend due to decreased rainfall. Moreover, this result shows that soil moisture can quickly respond to rainfall events.

Figure 9c shows changes in the correlation length between 7,500 and 21,000 m, representing changes in the spatial structure of soil moisture. During the rainfall season, because of the uneven distribution of rainfall, the spatial continuity of soil moisture was disrupted, and the correlation length decreased, suggesting that the spatial structure of soil moisture was divided into several homogeneous patterns, each of which displayed independent statistical characteristics (mean and standard deviation). 
After the rainfall season, the spatial continuity of soil moisture gradually increased, indicating that the spatial structure can be represented using fewer homogeneous patterns. Then, the extents of the patterns became larger, as expressed by the increase in the correlation length. However, the spatial structure of soil moisture remained stable from October 3 to October 17 because soil moisture was primarily affected by static factors such as topography and soil texture. During the period from October 14 to 17 , a very small amount of snow decreased the ATI, which resulted in a false change in the upscaled soil moisture; thus, snow cover decreased the correlation length.

The sills were similar to the variances in the soil moisture fields. Figure 9d shows that the sill varied between 0.001 and 0.01 and followed a well-defined seasonal trend. This trend was related to the processes that affect the mean soil moisture in the study area. In the rainy season, rainfall resulted in more uniform soil moisture patterns, and the sill was relatively steady and fluctuated slightly. After the summer, the sill continued to increase and was mainly affected by soil texture and evapotranspiration differences because of varying solar radiative inputs at different slope aspects.

The nugget represents the random component of the sill. Figure 9e shows that the nugget changes between 0 and $0.450 \times 10^{-3}$. The change in the nugget was not completely consistent with seasonal trends in the soil moisture, sill and correlation length. However, the nugget generally increased during wet conditions. The variability expressed by the nugget was much smaller than that of the sill, and the maximum nugget was less than $20 \%$ of the sill.

The spatial heterogeneity of the soil moisture was controlled by various factors in different seasons. In the rainy season, rainfall resulted in low soil moisture variability, with a temporally averaged sill of $0.170 \times 10^{-2} \mathrm{~cm}^{3} / \mathrm{cm}^{3}$ and a complex spatial structure with a temporally averaged correlation length of approximately $7,800 \mathrm{~m}$. After September 20 , the average variability increased to $0.460 \times 10^{-2} \mathrm{~cm}^{3} / \mathrm{cm}^{3}$, 
and other factors, such as soil texture, evapotranspiration, and topography, became important. The average correlation length was $16,200 \mathrm{~m}$, suggesting that these factors did not result in more homogeneous patterns than those in the rainy season. In the upscaling period, the average correlation length was 11,200 m, which was similar to the average distance between EHWSN nodes. This result suggests that it was difficult to interpolate spatio-temporal soil moisture data based on semivariograms.

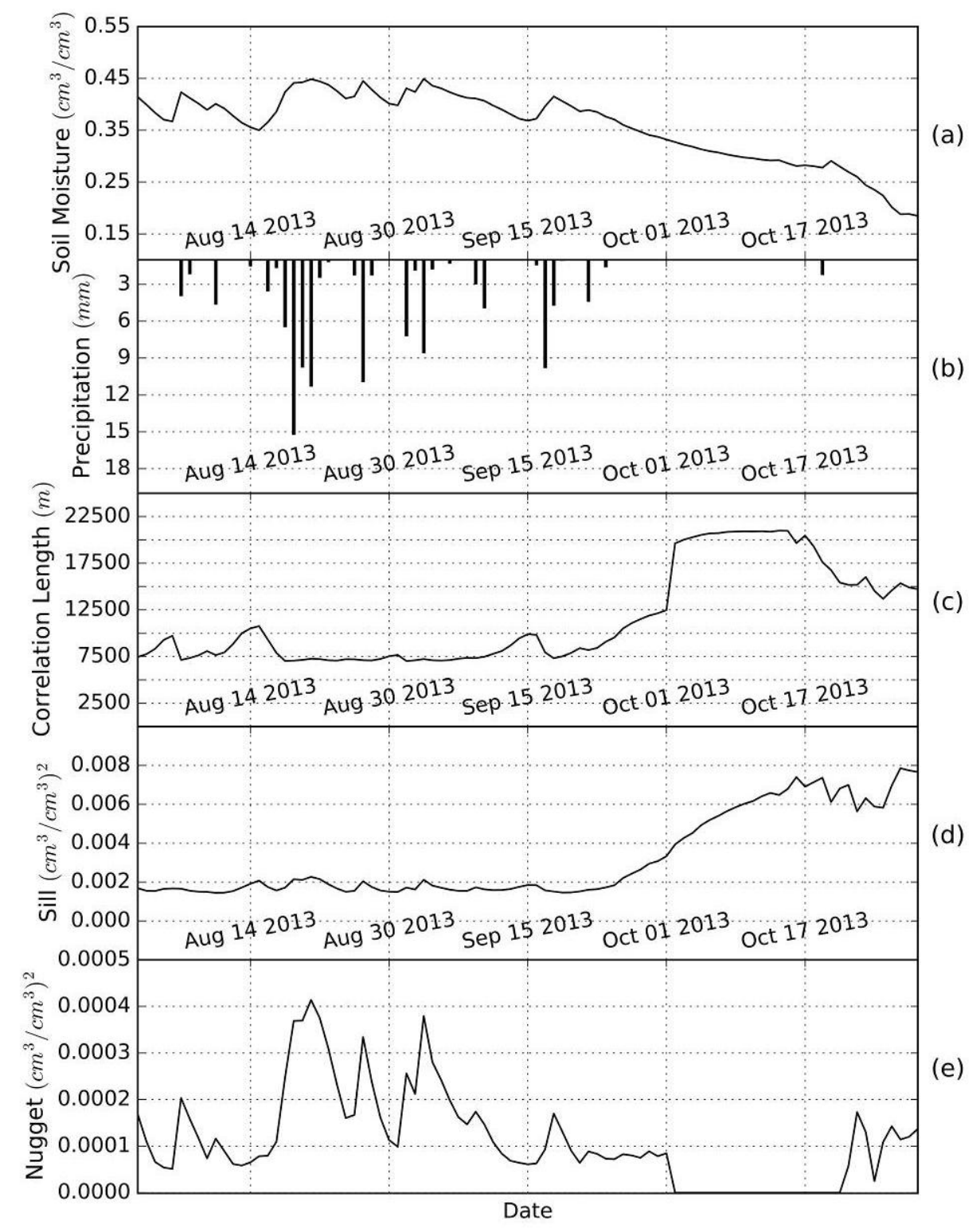

Figure 9. Temporal dynamics of the average soil moisture (a), precipitation (b), correlation length (c), sill (d), and nugget (e) in the Babao River Basin 


\subsubsection{EOF Analysis}

The EOF method was used to analyze time variations in the soil moisture mapping results. The data matrix $F$ in Equation (15) was constructed using the $1 \mathrm{~km}$ upscaled soil moisture data set. According to Equation (17), the error ranges of the eigenvalues were calculated based on a significance test, and no overlap was observed between adjacent error bars, as shown in Figure 10a, indicating that the eigenvalues were valid. The eigenvalues were ordered in descending order; then, the explanation of the variance was obtained. As shown in Figure 10b, the first six explained variances were computed, and the first two EOF models combined to account for $98.3 \%$ of the total daily soil moisture variance. They explained 88.7 and $9.6 \%$ of the variance, respectively. Hence, the two leading models were selected to analyze the mapping results of the spatio-temporal distribution of soil moisture.

(a)

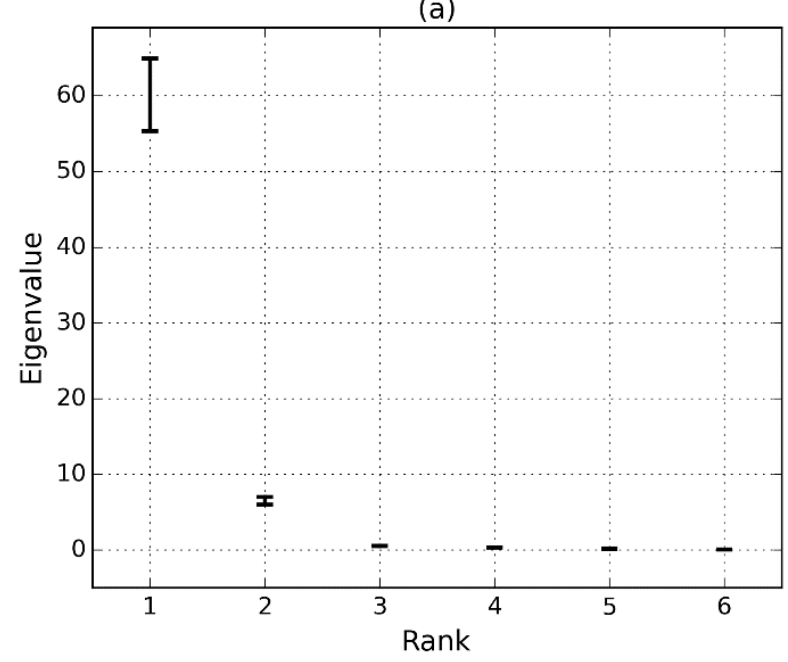

(b)

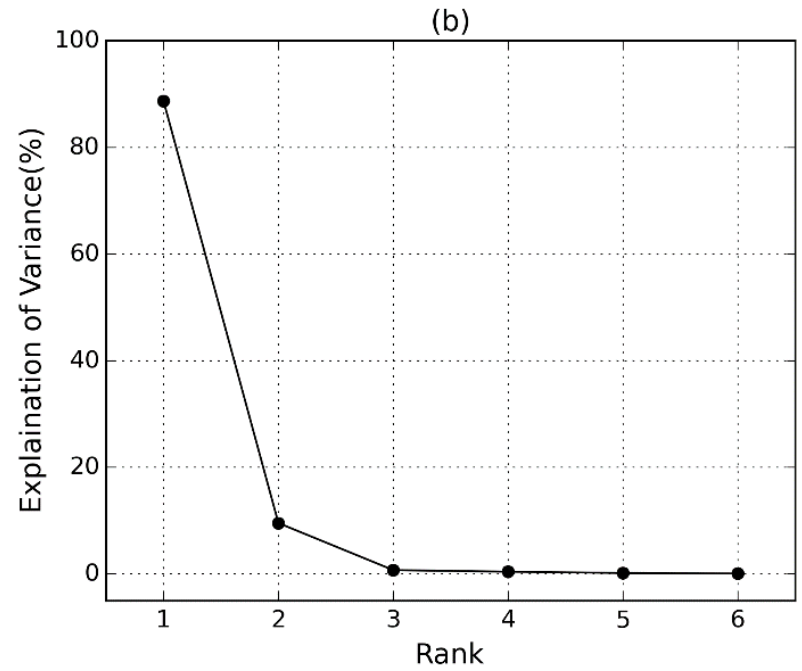

Figure 10. Eigenvalues and error bars (a) and explanation of variance (b) 
The first two EOF models are represented as maps labeled EOF1 and EOF2, and the time evolutions of both models were calculated using Equation (16) and are labeled PC1 and PC2 in Figure 11.

The EOF1 model exhibits a even pattern over the entire domain. The map of EOF1 is mostly positive, which indicates that the temporal evolution of the upscaled soil moisture is synchronous at most grid points. The synchronous evolution in time series is considered a systemic change, which is represented by PC1 in Figure 11. The trend in PC1 is consistent with changes in the average soil moisture, namely the seasonal cycle, as shown in Figure 9a.

The EOF2 model is composed of $20 \%$ negative values and $80 \%$ positive values that are close to 0 , which indicates that PC2 in Figure 11 supplements the dynamic characteristics of soil moisture at locations with negative values. PC1 and out-of-phase of PC2 in Figure 11 together exbhilit the temporal evolution of soil moisture at locations with negative values.

To identify the differences in the dynamics of soil moisture between locations with negative and positive values in the EOF2 map, Figure 11 shows how patterns at four different locations oscillate with time. The amplitude of the fluctuation was higher at locations with negative values (Figures $12 \mathrm{c}$ and $12 \mathrm{~d}$ ) than at those with positive values (Figures $12 \mathrm{a}$ and $12 \mathrm{~b}$ ). This finding may be due to orographic rain predominating at locations with negative values. In addition, a well-defined increase in soil moisture locations with negative values occurred from October 14 to October 20, which was caused by snowmelt.

Two time-dependent variation processes were isolated by the EOF method. The common characteristics of the time series changes at all locations were extracted to represent the low-frequency 
oscillation known as the seasonal cycle. The microclimate with strong precipitation resulted in higher time variations over twenty percent of the area compared to those in the remainder of the area.
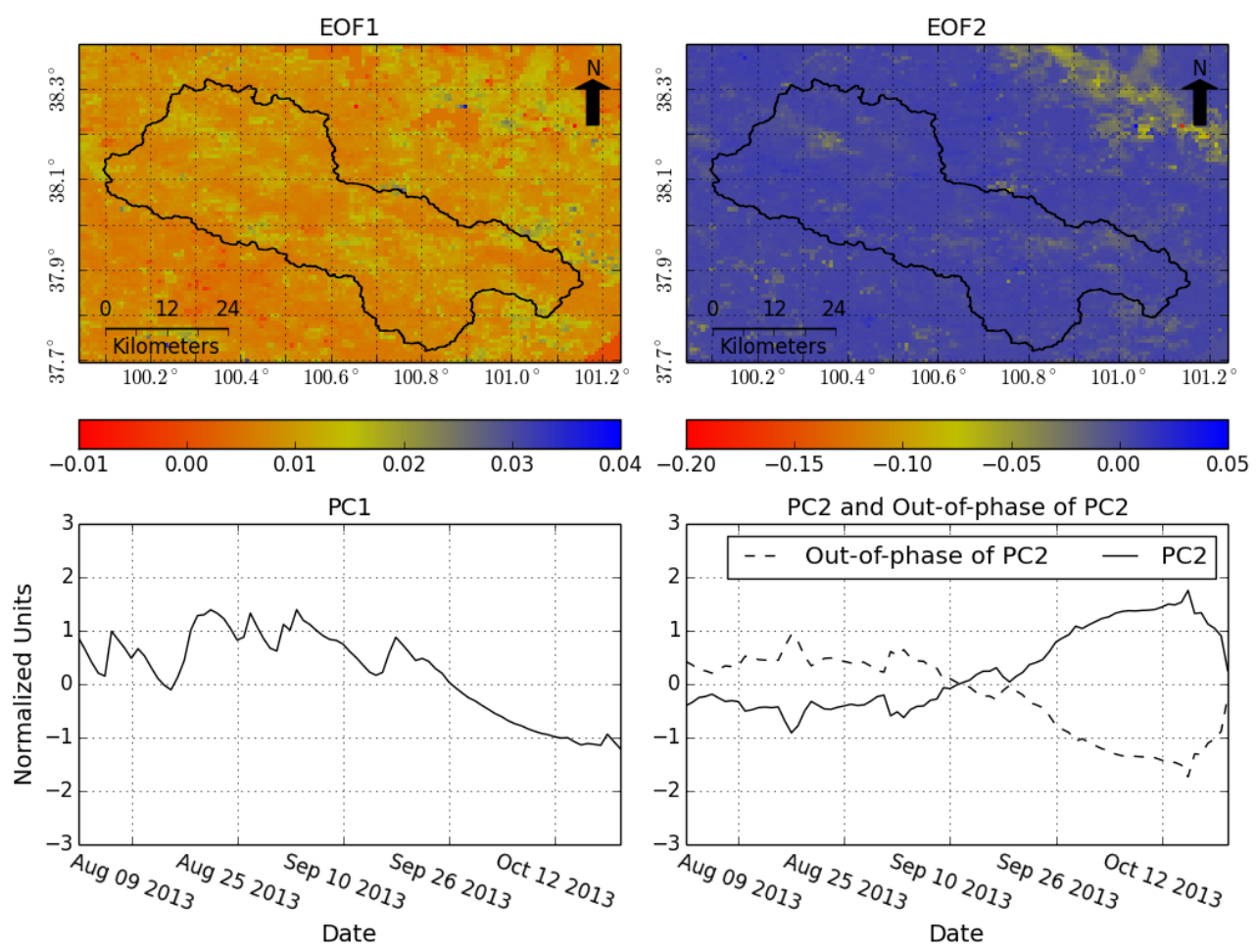

Figure 11. EOF models and corresponding temporal evolution processes 

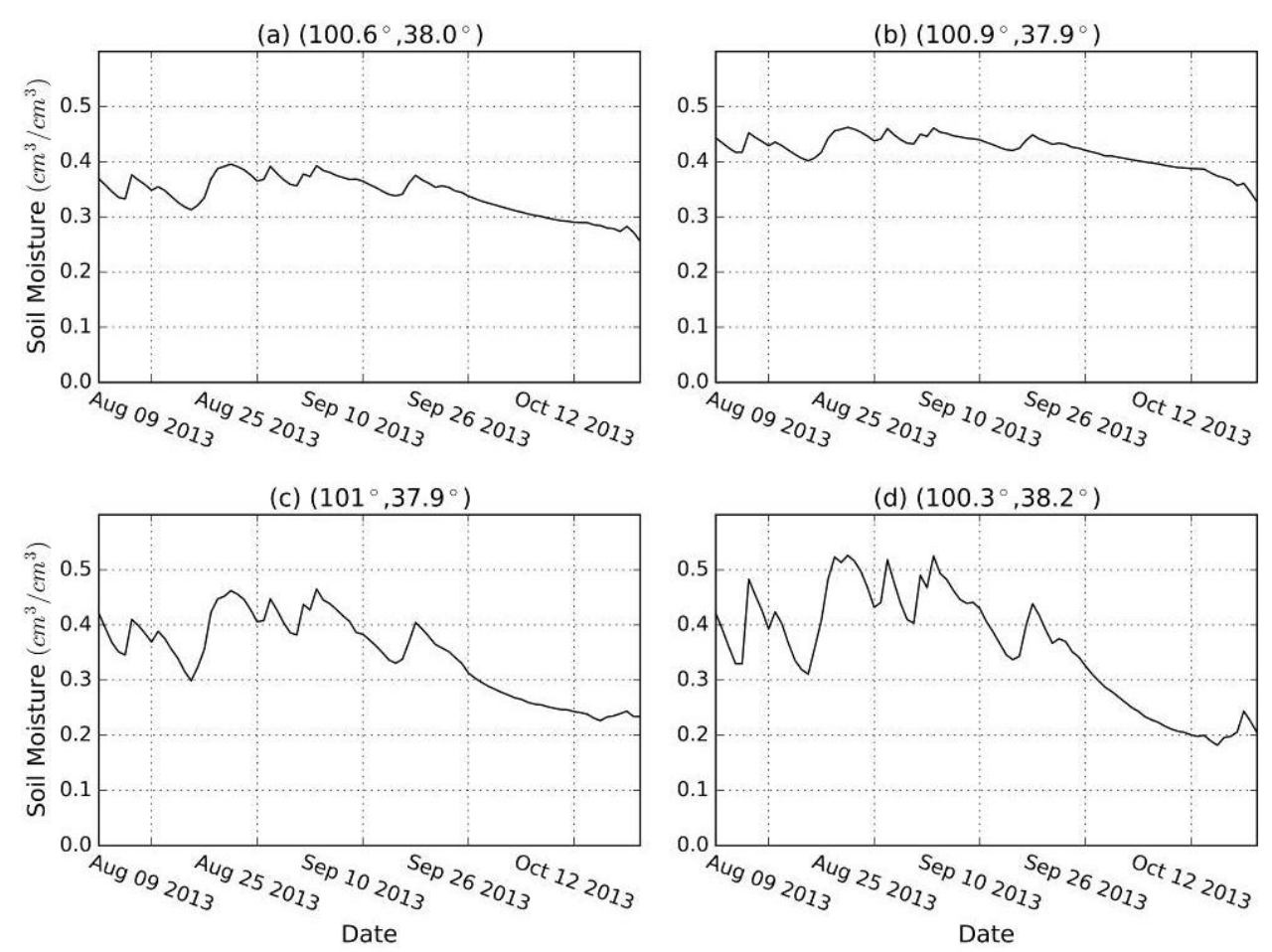

Figure 12. Oscillation of soil moisture at locations with positive (a, b) and negative (c, d) EOF2 values

\section{Conclusion}

An upscaling algorithm based on temporal information from multi-point observations and auxiliary remote sensing data related to soil moisture is extended to estimate $1 \mathrm{~km}$ soil moisture with spatio-temporal continuity. ATI is used as auxiliary information and transformed into a representative soil moisture data set to capture temporal changes in the upscaled soil moisture. The Bayesian estimation method is used to construct the relationship between the multi-point observations and upscaled soil moisture. This upscaling algorithm can overcome challenges related to soil moisture estimation based on sparse observations by introducing ATI time series information. However, if in-situ measurements are excessively sparse, it is difficult to establish the relationship between soil 
moisture and auxiliary information, and an accurate estimate of upscaled soil moisture cannot be obtained.

The ideal distribution of soil moisture products should have a high spatio-temporal resolution and high continuity, which is difficult to achieve, especially in mountainous areas with complex terrain. However, the upscaling algorithm produced an ideal space-time distribution of soil moisture in the Babao River Basin. In addition, the upscaled soil moisture with a $1 \mathrm{~km}$, daily resolution exhibited high estimation accuracy, including mean ubRMSE and $r$ values of 0.031 and 0.876 , respectively. Compared to current microwave soil moisture, the upscaled soil moisture exhibited higher accuracy, space-time continuity and resolution.

Comparing upscaled soil moisture data to other remote sensing products of soil moisture is a common way to evaluate mapping results. The upscaling of soil moisture at the $25 \mathrm{~km}$ scale is compared to the SMOS product, and the consistency of the time series is shown, with $r=0.719$. However, relative to the upscaled soil moisture, the SMOS soil moisture product in the study area is underestimated due to the complex terrain. The positive relationship between the RMSEs and the mean slope in the SMOS pixels is well defined. The upscaled soil moisture at the $25 \mathrm{~km}$ scale can be used to revise the SMOS soil moisture product using the relationship between the mean slopes in the SMOS pixels and the errors.

The $1 \mathrm{~km}$ upscaling results with satisfactory accuracy were subsequently used to analyze the spatio-temporal characteristics of soil moisture at the basin scale. The upscaled soil moisture not only represented the spatial autocorrelation but also captured the seasonal cycle, which was caused by introducing ATI into the upscaling process. The spatial-temporal variability of soil moisture was affected by rainfall in the rainy season and soil texture and evapotranspiration differences due to the 
various slope aspects in the dry season. The spatio-temporal analysis of the upscaled soil moisture indirectly displayed the reasonability of the estimation results.

In future studies, soil moisture products at a resolution of $1 \mathrm{~km}$ can be used to understand eco-hydrological processes, calibrate model parameters and perform data assimilation. In addition, this algorithm can generate multi-scale results for level-to-level accuracy evaluations of soil moisture remote sensing products at coarser resolutions. However, some problems exist in the upscaling algorithm. The key step in the algorithm is to obtain the upscaled samples of soil moisture. However, both factors maybe lead to inaccurate upscaled samples. First, the relationship between in-situ soil moisture and pixel ATI is built at mismatched scales, which influences the sample accuracy. Second, upscaled samples may not yield accurate time variability associated with upscaled soil moisture if too maeny samples are missing due to cloud cover. These problems will be solved in future research.

\section{Acknowledgments}

This work was supported by the National Natural Science Foundation of China (41531174), the CAS Interdisciplinary Innovation Team of the Chinese Academy of Sciences (QYZDY-SSW-DQC011), Natural Science Foundation of China (41471357) and National Natural Science Foundation of Gansu Province (1501RJZA013).

MODIS 8-day surface reflectance (MOD09A1) and daily land surface temperature (MOD11A1) data were retrieved from the online Data Pool, courtesy of the NASA Land Processes Distributed Active Archive Center (LP DAAC), USGS/Earth Resources Observation and Science (EROS) Center, Sioux Falls, South Dakota, https://e4ft101.cr.usgs.gov. The SMOS soil moisture was provided by the Barcelona Expert Centre (http://cp34-bec.cmima.csic.es/). 


\section{References}

Anderson, S. P., Bales, R. C., \& Duffy, C. J. (2008). Critical zone observatories: Building a network to advance interdisciplinary study of earth surface processes. Mineralogical Magazine, 72, 7-10. doi:10.1180/minmag.2008.072.1.7.

Bakushinskii, A. B. (1984). Remarks on choosing a regularization parameter using the quasi-optimality and ratio criterion. USSR Computational Mathematics and Mathematical Physics, 24, 181-182. doi:10.1016/0041-5553(84)90253-2.

Bárdossy, A., \& Lehmann, W. (1998). Spatial distribution of soil moisture in a small catchment. Part 1: geostatistical analysis. Journal of Hydrology, 206, 1-15. doi:10.1016/S0022-1694(97)00152-2.

Dunne, T., Moore, T., \& Taylor, C. (1975). Recognition and prediction of runoff-producing zones in humid regions. Hydrological Science-Bulletin-des Sciences Hydrologiques, 20, 305-327.

Gao, S., Zhu, Z., Liu, S., Jin, R., Yang, G., \& Tan, L. (2014). Estimating the spatial distribution of soil moisture based on Bayesian maximum entropy method with auxiliary data from remote sensing. International Journal of Applied Earth Observation and Geoinformation, 32, 54-66. doi:10.1016/j.jag.2014.03.003.

Ge, Y., Wang, J. H., Heuvelink, G. B. M., Jin, R., Li, X., \& Wang, J. F. (2015). Sampling design optimization of a wireless sensor network for monitoring ecohydrological processes in the Babao River basin, China. International Journal of Geographical Information Science, 29, 92-110. doi:10.1080/13658816.2014.948446.

Golub, G. H., Heath, M., \& Wahba, G. (1979). Generalized cross-validation as a method for choosing a good ridge parameter. Technometrics, 21, 215-223. doi:10.1080/00401706.1979.10489751. 
Hannachi, A. (2004). A primer for EOF analysis of climate data. Department of Meteorology, University of Reading, 1-33.

Hansen, P. C. (1998). Rank-deficient and discrete ill-posed problems: Numerical aspects of linear inversion. Philadelphia, PA, USA: Society for Industrial and Applied Mathematics.

Hansen, P. C., Nagy, J. G., \& Leary, D. P. (2007). Deblurring images: Matrices, spectra and filtering. Philadelphia, PA, USA: Society for Industrial and Applied Mathematics. doi:10.1117/1.2900557.

Hengl, T. (2007). A practical guide to geostatistical mapping of environmental variables. Amsterdam: University of Amsterdam.

Jin, R., Li, X., Yan, B., Li, X., Luo, W., Ma, M., Guo, J., Kang, J., Zhu, Z., \& Zhao, S. (2014). A nested ecohydrological wireless sensor network for capturing the surface heterogeneity in the midstream areas of the Heihe River Basin, China. IEEE Geoscience and Remote Sensing Letters, 11, 2015-2019. doi:10.1109/LGRS.2014.2319085.

Journel, A. G., \& Huijbregts, C. J. (1978). Mining geostatistics. London, UK: Academic Press.

Kalnay, E., Kanamitsu, M., Kistler, R., Collins, W., Deaven, D., Gandin, L., Iredell, M., Saha, S., White, G., \& Woollen, J., Zhu, Y., Leetmaa, A., Reynolds, R., Chelliah, M., Ebisuzaki, W., Higgins, W., Janowiak, J., Mo, K. C., Ropelewski, C., \& Wang, J. (1996). The NCEP/NCAR 40-year reanalysis project. Bulletin of the American Meteorological Society, 77, 437-471. doi:10.1175/1520-0477(1996)077<0437:TNYRP>2.0.CO;2.

Kang, J., Jin, R., \& Li, X. (2015). Regression kriging-based upscaling of soil moisture measurements from a wireless sensor network and multiresource remote sensing information over 
heterogeneous cropland. IEEE Geoscience and Remote Sensing Letters, 12, 92-96. doi:10.1109/LGRS.2014.2326775.

Kang, J., Li, X., Jin, R., Ge, Y., Wang, J., \& Wang, J. (2014). Hybrid optimal design of the eco-hydrological wireless sensor network in the middle reach of the Heihe River Basin, China. Sensors (Basel, Switzerland), 14, 19095-19114. doi:10.3390/s141019095.

Kumar, K., Arora, M. K., \& Hariprasad, K. S. (2016). Geostatistical analysis of soil moisture distribution in a part of Solani River catchment. Applied Water Science, 6, 25-34. doi:10.1007/s13201-014-0202-x.

Li, X., Cheng, G., Liu, S., Xiao, Q., Ma, M., Jin, R., Che, T., Liu, Q., Wang, W., \& Qi, Y. (2013). Heihe watershed allied telemetry experimental research (HiWATER): Scientific objectives and experimental design. Bulletin of the American Geological Society, 94, 1145-1160.

Liang, S. (2001). Narrowband to broadband conversions of land surface albedo I: Algorithms. Remote Sensing of Environment, 76, 213-238. doi:10.1016/S0034-4257(00)00205-4.

Ma, C., Wang, W., Han, X., \& Li, X. (2013). Soil moisture retrieval in the Heihe River Basin based on the real thermal inertia method. IEEE Journal of Selected Topics in Applied Earth Observations and Remote Sensing, 6, 1460-1467. doi:10.1109/JSTARS.2013.2252149.

North, G. R., Bell, T. L., Cahalan, R. F., \& Moeng, F. J. (1982). Sampling errors in the estimation of empirical orthogonal functions. Monthly Weather Review, 110, 699-706. doi:10.1175/1520-0493(1982)110<0699:SEITEO>2.0.CO;2.

Onogi, K., Tsutsui, J., Koide, H., Sakamoto, M., Kobayashi, S., Hatsushika, H., Matsumoto, T., Yamazaki, N., KAMAHORI, H., \& Takahashi, K., Kadokura, S., Wada, K., Kato, K., Oyama, 
R., Ose, T., Mannoji, N., \& Taira, R. (2007). The JRA-25 reanalysis. Journal of the Meteorological Society of Japan, 85, 369-432. doi:10.2151/jmsj.85.369.

Peters, J., De Baets, B., De Clercq, E. M., Ducheyne, E. M., \& Verhoest, N. E. (2011). The potential of multitemporal aqua and Terra MODIS apparent thermal inertia as a soil moisture indicator. International Journal of Applied Earth Observation and Geoinformation, 13, 934-941. doi:10.1016/j.jag.2011.07.003.

Pratola, C., Barrett, B., Gruber, A., Kiely, G., \& Dwyer, E. (2014). Evaluation of a global soil moisture product from finer spatial resolution SAR data and ground measurements at Irish sites. Remote Sensing, 6, 8190-8219. doi:10.3390/rs6098190.

Qin, J., Yang, K., Lu, N., Chen, Y., Zhao, L., \& Han, M. (2013). Spatial upscaling of in-situ soil moisture measurements based on MODIS-derived apparent thermal inertia. Remote Sensing of Environment, 138, 1-9. doi:10.1016/j.rse.2013.07.003.

Reichle, R. H., Koster, R. D., Dong, J., \& Berg, A. A. (2004). Global soil moisture from satellite observations, land surface models, and ground data: Implications for data assimilation. Journal of Hydrometeorology, 430-442. doi:10.1175/1525-7541(2004)005<0430:GSMFSO>2.0.CO;2.

Rodríguez-Iturbe, I., \& Porporato, A. (2004). Ecohydrology of water-controlled ecosystems: Soil moisture and plant dynamics. Cambridge, UK: Cambridge University Press.

Rodriguez-Iturbe, I., Porporato, A., Laio, F., \& Ridolfi, L. (2001). Plants in water-controlled ecosystems: Active role in hydrologic processes and response to water stress: I. Scope and general outline. Advance in Water Resources, 24, 695-705. doi:10.1016/S0309-1708(01)00004-5. 
Rui, H., \& Beaudoing, H. (2011). Readme document for global land data assimilation system version 2 (GLDAS-2) products. GES DISC.

Sandells, M. J., Davenport, I. J., \& Gurney, R. J. (2008). Passive L-band microwave soil moisture retrieval error arising from topography in otherwise uniform scenes. Advance in Water Resources, 31, 1433-1443. doi:10.1016/j.advwatres.2008.01.012.

Uppala, S. M., KAllberg, P. W., Simmons, A. J., Andrae, U., Bechtold, V. D. C., Fiorino, M., Gibson, J. K., Haseler, J., Hernandez, A., \& Kelly, G. A., Li, X., Onogi, K., Saarinen, S., Sokka, N., Allan, R. P., Andersson, E., Arpe, K., Balmaseda, M. A., Beljaars, A. C. M., \& Berg, L. V. D. (2005). The ERA-40 re-analysis. Quarterly Journal of the Royal Meteorological Society, 131, 2961-3012. doi:10.1256/qj.04.176.

Veroustraete, F., Li, Q., Verstraeten, W. W., Chen, X., Bao, A., Dong, Q., Liu, T., \& Willems, P. (2012). Soil moisture content retrieval based on apparent thermal inertia for Xinjiang province in China. International. Journal of Remote Sensing, 33, 3870-3885. doi:10.1080/01431161.2011.636080.

Verstraeten, W. W., Veroustraete, F., van der Sande, C. J., Grootaers, I., \& Feyen, J. (2006). Soil moisture retrieval using thermal inertia, determined with visible and thermal spaceborne data, validated for European forests. Remote Sensing of Environment, 101, 299-314. doi:10.1016/j.rse.2005.12.016.

Wagner, W., Scipal, K., Pathe, C., Gerten, D., Lucht, W., \& Rudolf, B. (2003). Evaluation of the agreement between the first global remotely sensed soil moisture data with model and precipitation data. Journal of Geophysical Research, 108, 4611. doi:10.1029/2003JD003663. 
Western, A. W., Blöschl, G., \& Grayson, R. B. (1998). Geostatistical characterisation of soil moisture patterns in the Tarrawarra catchment. Journal of Hydrology, 205, 20-37. doi:10.1016/S0022-1694(97)00142-X.

Western, A. W., Zhou, S., Grayson, R. B., McMahon, T. A., Blöschl, G., \& Wilson, D. J. (2004). Spatial correlation of soil moisture in small catchments and its relationship to dominant spatial hydrological processes. Journal of Hydrology, 286, 113-134. doi:10.1016/j.jhydrol.2003.09.014.

Yao, X., Fu, B., Lü, Y., Sun, F., Wang, S., \& Liu, M. (2013). Comparison of four spatial interpolation methods for estimating soil moisture in a complex terrain catchment. PloS one, 8, e54660

Zacharias, S., Bogena, H., Samaniego, L., Mauder, M., Fuß, R., Pütz, T., Frenzel, M., Schwank, M., Baessler, C., \& Butterbach-Bahl, K., Bens, O., Borg, E., Brauer, A., Dietrich, P., Hajnsek, I., Helle, G., Kiese, R., Kunstmann, H., Klotz, S., \& Munch, J. C. (2011). A network of terrestrial environmental observatories in Germany. Vadose Zone Journal, 10, 955-973. doi:10.2136/vzj2010.0139.

\section{List of Figure Captions}

Figure 1. Map of the Babao River Basin and the distribution of the EHWSN nodes

Figure 2. Mapping procedure of spatio-temporal soil moisture in the Babao River Basin

Figure 3. Relationship between the MODIS-derived ATI and EHWSN soil moisture observations

Figure 4. ATI (a) and representative soil moisture (b) in the Babao River Basin

Figure 5. Spatio-temporal mapping results of $1 \mathrm{~km}$ soil moisture in the Babao River Basin

Figure 6. Temporal evolution of the fluctuations in upscaled soil moisture and AWS observations 
Figure 7. Scatterplots of re-sampled soil moisture at a resolution of $25 \mathrm{~km}$ and soil moisture from the SMOS product from August 2013 to October 2013

Figure 8. Examples of the theoretical (line) and experimental (marker) semivariograms of upscaled soil moisture at a resolution of $1 \mathrm{~km}$

Figure 9. Temporal dynamics of the average soil moisture (a), precipitation (b), correlation length (c), sill (d), and nugget (e) in the Babao River Basin

Figure 10. Eigenvalues and error bars (a) and explanation of variance (b)

Figure 11. EOF models and corresponding temporal evolution processes

Figure 12. Oscillation of soil moisture at locations with positive (a, b) and negative (c, d) EOF2 values 